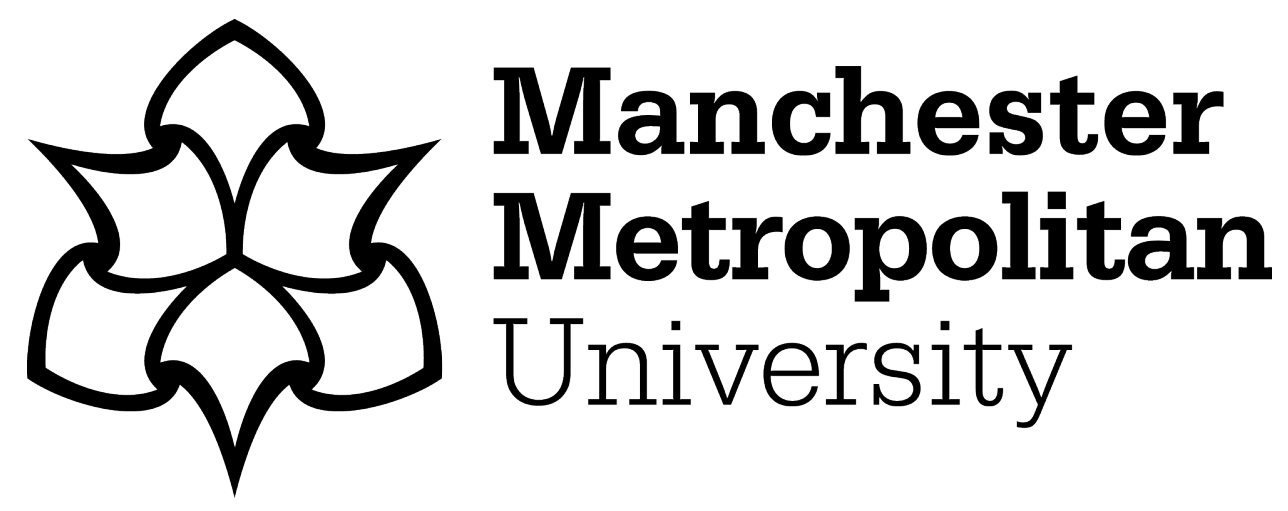

Kim, M, Lee, CK and Jung, Timothy ORCID logoORCID: https://orcid.org/0000-0002-8594-6641 (2019) Exploring Consumer Behavior in Virtual Reality Tourism Using an Extended Stimulus-Organism-Response Model. Journal of Travel Research, 59 (1). pp. 69-89. ISSN 0047-2875

Downloaded from: https://e-space.mmu.ac.uk/621893/

Version: Accepted Version

Publisher: SAGE Publications

DOI: https://doi.org/10.1177/0047287518818915

Please cite the published version 


\title{
Exploring Consumer Behavior in Virtual Reality Tourism Using an Extended Stimulus- Organism-Response Model
}

\begin{abstract}
Although virtual reality (VR) is an emerging technology in tourism, little research has conducted on what factors make consumers visit locations presented by VR. To address this gap in the literature, this study developed a theoretical framework including authentic experience, cognitive and affective responses, attachment, and visit intention with VR tourism using a stimulus-organism-response (SOR) theory. The results revealed significant impacts of authentic experience on cognitive and affective responses, indicating that authentic experience is an important factor in VR tourism. The study identified cognitive and affective responses as significant mediators in predicting attachment and visit intention. The results demonstrated that the intention to visit places shown in VR tourism was influenced by attachment to VR. Cognitive response was a stronger influence than affective response on the intention to visit a destination in VR. This study sheds light on why potential tourists visit destinations shown in VR.
\end{abstract}

\section{Keywords}

virtual reality tourism, stimulus-organism-response theory, authentic experience, attachment, visit intention 


\section{Introduction}

Virtual reality (VR) tourism, using the three-dimensional (3D) world of an innovative technology, is formed via a combination of visual, kinetic, and audio elements so that users can actually experience a real object from a tourist perspective (Williams and Hobson 1995). VR functions play a key role in tourist experience and behavior, such as interplanetary voyages, trips to fantasy worlds, sporting events, and large theme parks (Dewailly 1999). Through the use of VR tourism, people can travel anywhere using VR applications and wearing VR devices (Stanley 2017; Tussyadiah et al. 2018). Since the first research was conducted on VR tourism in 1995, researchers have been interested in the advantages that VR offers marketing techniques (Dewailly 1999; Hobson and Williams 1995; Williams and Hobson 1995). Some studies on VR tourism have paid attention to consumer behavior, such as enjoyment of VR content and the choice of a destination portrayed in VR (Guttentag 2010; Lee and Oh 2007). In recent years, tourism scholars have examined the acceptance of VR technology (Huang et al. 2013, 2016) as well as attitude changes through VR tourism (Tussyadiah et al. 2018). Although VR technology has demonstrated its capability and potential as a useful marketing tool, more theoretical studies on VR consumer behavior are necessary to identify which factors encourage potential tourists to visit destinations shown in VR.

A stimulus-organism-response (SOR) theory may be a useful framework to explore the factors associated with VR. The SOR theory has been widely used to examine the links among inputs (stimulus), processes (organism), and outputs (response). In various disciplines, research using the SOR theory has been conducted on servicescapes (Bitner 1992), arousal and pleasure (Mehrabian and Russell 1974), and aesthetics (Wohlwill 1976). Some tourism studies have been conducted on visitor behavior using the SOR model (e.g., Jang and Namkung 2009; Jani and Han 2015; Kim and Moon 2009). The SOR framework has been 
found to be suitable to elucidate tourists' behaviors in the context of theme parks (Chang, Shu, and King 2014) and motion pictures (Rajaguru 2014). Furthermore, past research has utilized the extended SOR model to predict consumer behavior by incorporating additional variables such as cognition and perceived service quality (Jacoby 2002; Kim and Moon 2009). More importantly, the SOR theory has broadly predicted user behavior when using information and communication technologies. Specifically, the SOR theory in relation to innovative technologies has been applied to impulsive buying behavior in a mobile auction (Chen and Yao 2018), customer engagement with online brand community characteristics (Islam and Rahman 2017), co-creation in social media communities (Kamboj, Sarmah, Gupta, and Dwivedi 2018), online shipping behavior (Peng and Kim 2014), and customer loyalty in online social commerce (Wu and Li 2018). In the context of VR tourism, this study investigates potential tourists' behavior based on an extended SOR model that comprises a stimulus (authentic experience), process (cognitive and affective response), and output (attachment to VR and visit intention).

The quality of authenticity is critical to enhance tourists' VR experiences (Guttentag 2010) because some tourism experiences involving VR tourism activities may not be perceived as authentic due to the poor quality of the technology used. Moreover, tourists perceive physical and sensory participation as an important component of experiencing an appropriate level of authenticity in virtual tourism (Mura, Tavakoli, and Sharif 2017). In addition, the high degree of perceived authenticity of VR tourism shifts the focus from how to travel to how to meet, surpassing the physical boundaries of corporeal travel (Yung and KhooLattimore 2017). Authenticity is an essential antecedent to explain souvenir-purchasing intention (Lin and Wang 2012) and the experience of local culture, customs, and atmosphere (Nguyen and Cheung 2016). Moreover, authentic experience plays a significant role in 
predicting slow tourists' behavioral intention (Meng and Choi 2016a, 2016b) and post-visit online reviews (Mkono 2013).

Attachment, which is a fundamental human need (Maslow 1943), has a significant effect on consumers' behavior (Orth, Limon, and Rose 2010) and tourists' choice of destination (Ramkissoon 2015). In digital tourism environments, attachment to online/mobile sites, mobile devices, and social media plays a key role in anticipating consumer behavior on online/mobile sites (Kim et al. 2015; Kim et al. 2016a), mobile device usage (Kim et al. 2016c), and social media (Kim, Lee, and Bonn 2016; Kim, Lee, and Bonn 2017; Kim, Lee, and Preis 2016). Authentic experiences from VR tours (e.g., Dueholm and Smed 2014; Guttentag 2010; Mura, Tavakoli, and Sharif 2017; Yung and Khoo-Lattimore 2017) and attachment to VR games (e.g., Oleksy and Wnuk 2017; Wolfendale 2007) play important roles in illuminating consumers' behavior in digital tourism environments, but these roles have not yet been verified in VR tourism based on the SOR theory.

To bridge this gap in the literature, this study examines authentic experience as a stimulus, cognitive and affective response as an organism, attachment to VR tourism experiences as a response, and behavioral intention as a response among potential tourists using the extended SOR framework. The purpose of this research is to investigate which factors encourage potential tourists to visit destinations shown in VR from the perspectives of authentic experience and attachment. Specifically, this study has a three-fold purpose: (1) to validate the influence of authentic experience on cognitive and affective responses to tourism-related VR experiences among VR tourists using the SOR theory; (2) to examine the impacts of cognitive response on affective response as well as cognitive and affective responses to VR tourism experiences on attachment to VR and visit intention to the destination presented in VR; and (3) to investigate the influence of attachment to VR in predicting potential tourists' behavioral intention depicted in VR. In this study, the term tourism-related VR activities refers to the use 
of VR devices to play, enjoy, experience, travel, and explore information by looking at pictures, gaming, watching 3D 360-degree videos, watching drone videos, looking at holographic images, and other tourism-related activities. The categories of tourism-related activities include the following: leisure activities and movies, amusements and games, overseas or domestic travel, space and underwater tours, exhibitions and entertainments, festivals and events, sports and expos, resorts and cruises, and recreation and theme parks.

The findings of this study may shed light on the roles of authentic experience and attachment in predicting potential tourist behavior in VR tourism using the extended SOR model. Additionally, this study explains that VR tourism can provide consumers with the opportunity to experience the destinations or attractions presented in VR. More importantly, this study contributes to articulating the distinctiveness of VR tourism as a virtual representation of an actual attraction, destination, or visitor experience that is designed as a prelude to visitation or that extends consumers' previous experiences. With regard to the distinctiveness of VR tourism in relation to other disciplines, this research contributes by showing that consumers increasingly participate in VR tourism activities as a new technology for hedonic stimuli (e.g., enjoyment, emotional involvement, flow state). In addition, this study provides managerial implications for VR tourism stakeholders. Moreover, the results of this research offer marketing strategies to the tourism industry by considering consumer behavior in VR tourism experiences. Specifically, developers of VR tourism content could focus on generating authentic experiences that lead to cognitive and affective responses, resulting in VR users' attachment and visit intention to tourism destinations.

\section{Literature Review}

Theoretical Background 
Virtual reality (VR) tourism. VR can be defined in the tourism context as an interactive digital-generated medium that enables partakers to create simulated experiences of unreal environments using a head-mounted display (HMD) of a VR device (Hobson and Williams 1995). As technology develops, VR tourism provides more complete pictures of hotels and destinations and reduces customers' perceived anxiety or risk by familiarizing consumers with unfamiliar destinations (Lee and Oh 2007). VR has been used in six principal tourism-related areas: planning and management, heritage preservation, marketing, accessibility, education, and entertainment (Guttentag 2010). Additionally, as a commercial tool, VR has been applied in the tourism industry to communicate with visitors by providing information about destinations (Huang et al. 2013) and online shopping retailers (e.g., Alibaba, Ebay, IKEA, LEGO) (Poremba 2017; Rick 2017).

In recent years, the 3D virtual world has provided opportunities for destination marketing organizers to connect with potential visitors by providing a rich experience that enables prospective tourists to search tourism destinations (Huang et al. 2016). VR tourism offers potential travelers the opportunity to experience spaces, adventures, attractions, and special events from the comfort of their homes before making the decision to visit (Stanley 2017). The effective use of VR tourism in cultural heritage destinations provides co-creative value in tourists' pre-, onsite, and post-visit experiences (Jung and tom Dieck 2017). In the tourism context (e.g., national parks, museums, domestic and international tourist destinations), VR has enjoyed a significant upswing of interest from researchers and businesses (Jung et al. 2016; Jung et al. 2017; Tussyadiah et al. 2018). Although VR has had an important impact on tourism-related domains, few studies have examined the factors that encourage VR tourists to visit the destinations presented in VR tourism. Thus, this research uses the SOR theory to address the gap in the literature by examining the effect of authentic experience on cognitive and affective responses, which also influence attachment to VR tourism experiences and visit 
intention to the destinations shown in VR tourism activities by potential consumers who experience VR tourism.

Stimulus-organism-response (SOR) theory. According to the SOR theory (see Figure 1), individuals react to environments in one of two general ways: approach behaviors include all positive actions, such as the desire to explore, stay, affiliate, or work, whereas averting behaviors include the opposite, such as the desire not to positively act (Mehrabian and Russell 1974). The SOR theory accentuates the emotion-eliciting or emotional qualities of surroundings that are regarded as aesthetic incitements (Wohlwill 1976). Whereas Mehrabian and Russell (1974) focused only on emotional responses, Bitner (1992) incorporates cognition and physiology within the SOR theory, expanding its application to servicescapes. More recently, an integrative SOR framework was presented with cognitive and affective systems that incorporate all previous engaged experiences that involve long-term memory (Jacoby 2002). Kim and Lennon (2013) extend Mehrabian and Russell's SOR theory to include internal (website quality) and external (reputation) sources of information as stimuli that affect purchase intention (response) through consumers' (organisms') cognition and emotion.

\section{Insert Figure 1 here}

In the tourism-related field, to address the need for a comprehensive assessment of restaurant quality, Jang and Namkung (2009) extend Mehrabian and Russell's SOR model by including restaurant-specific stimuli and measures of emotion. With regard to the SOR model, Kim and Moon (2009) suggest that servicescapes lead to customers' positive-negative behaviors of experience via cognitive and affective processes in a theme restaurant. Using the SOR model, Chang, Shu, and King (2014) find that the more authentic theme park guests 
think physical environments are, the greater their degree of perceived value of purchasing (hedonic and utilitarian values) and the greater their behavioral intention to revisit the park. Among motion picture audiences, the SOR model predicts visual as well as vocal impacts on tourism motivation as incitements and the relationship between intent to travel and actual visits as responses (Rajaguru 2014). In the tourism-related context, the SOR model is highly efficacious in explaining the relationships among stimuli (i.e., hotel ambience), process (i.e., emotions), and response (i.e., hotel loyalty) (Jani and Han 2015). In association with the literature, the current study develops and tests an extended SOR model to predict potential tourists' behavior in VR tourism.

Authentic experience. Authenticity is defined as a new consumer sensibility that involves perceptions of the extent to which novel, real, original, exceptional, and unique experiences, services, or products are genuine (Gilmore and Pine 2007). Specifically, authenticity refers to something that is genuine and novel rather than counterfeit in the context of physical objects (Cohen 1988). Authenticity as a post-modern style is related to "the concept of existential authenticity, which is defined as an existential state of being that is to be activated by tourism" (Wang 1999, 359). In the digital era, individuals want to be actors more than passive consumers, suggesting that customers obtain more memorable experiences when their senses are more actively engaged (Pine and Gilmore 1999). Authentic experience is the key factor in favorable conditions for competition in service industries (Gilmore and Pine 2007). Consumers buy experiences, services, or products according to their recognition of authenticity. Consumers also seek escape experiences that allow them to be fully immersed rather than simply educated and entertained (Pine and Gilmore 2015).

The concept of authenticity was introduced to sociological studies of tourist motivations and experiences several decades ago (Wang 1999). Since then, authenticity has been an active 
topic of study among tourism researchers (e.g., Meng and Choi 2016a, 2016b; Novello and Fernandez 2016). The tourism-related context includes substantial literature on authenticity. For example, perceived authenticity is a vital cause of perceived value, which in turn leads to souvenir-purchasing intention at destinations (Lin and Wang 2012). At heritage destinations, several aspects of authenticity have been identified, including appearance/physical settings, tourist facilities/commodification, local culture and customs, and atmosphere (Nguyen and Cheung 2016). Authenticity-related variables (knowledge, perception of authenticity, and information search behavior) have important associations with slow tourists' intention in tourists' decision-making processes (Meng and Choi 2016b). Meng and Choi (2016a) extended the theory of planned behavior by incorporating authentic awareness to elucidate the development of behavioral intention in slow tourists. Based on post-visit online reviews, Mkono (2013) highlights the importance of tourists' authentic experience with cultural objects as well as active participation.

In the virtual context of computer game users, a more authentic environment results in a higher degree of immersion and entertainment value (Pietschmann, Valtin, and Ohler 2012). In 3D virtual learning settings, more authentic contexts lead to better immersive experience (Lan and Liao 2018). Moreover, visitors' awareness of the authenticity of VR tourism is one factor in their approval of VR tourism as a substitute for genuine experience (Guttentag 2010). Dueholm and Smed (2014) assert that heritage sites can be strengthened as tourist attractions by paying attention to an appropriate degree of perceived authenticity through the implementation of new technologies (e.g., VR, augmented reality). Mura, Tavakoli, and Sharif (2017) find that VR tourism environments are not perceived as completely unrealistic, and participants perceive physical and sensorial involvements as an important component of experiencing authenticity in virtual tourism. Yung and Khoo-Lattimore (2017) suggest that a high level of perceived authenticity of VR content provides valuable insights into the 
trajectory of virtual tourism. Further, studies in virtual environments have documented the influence of immersion on authentic experience in terms of improving learners' engagement (Loup et al. 2016), in the comparison of a headband, 3D glasses, and a head-mounted display (Kronqvist, Jokinen, and Rousi 2016), and in tourism technology engagement (Schaffer 2017). Despite the significant role of authentic experience in VR tourism, no empirical research has been conducted on the impact of authentic experience on VR tourists' behavior. To address this gap, the present research investigates the influence of authentic experience as a stimulus in VR tourism on potential consumers' behavior by applying an extended SOR model.

Attachment. Attachment has been defined as "the tendency of human beings to make solid affectional bonds to particular people and objects" (Bowlby 1977, 201). Attachment in tourism refers to the affective and positive ties developed from individual connections with a destination (Ramkissoon 2015). In the context of virtual worlds, avatar attachment in gaming is expressive of identity and self-conception and thus can have moral significance similar to real-life attachments (Wolfendale 2007). In location-based augmented reality games (e.g., Pokémon Go), the satisfaction of playing and the social relations made during play can predict place attachment. Furthermore, the relations among game satisfaction, social relations, and place attachment are mediated by the appraisal of a place as exciting (Oleksy and Wnuk 2017).

With regard to on-site smartphone use, highly innovative travelers are open to recommendations when making on-site decisions, making them an effective target for context-based marketing (Tussyadiah 2016) and resulting in their attachment to mobile devices. With regard to attachment to mobile devices, Lalicic and Weismayer (2018) find that affective feelings derived from mobile phone usage are enhanced by effective travel-related applications, which encourage modern tourists while travelling, whereas the socialness of mobile phones significantly affects passionate behavior and affective outcomes. In online 
tourism shopping environments, attachment to online shopping sites plays a key role in increasing altruism and faithfulness to sites (Kim et al. 2015). In the context of the elaboration likelihood model, attachment to mobile tourism shopping companies influences the continued use of these companies (Kim et al. 2016a). For individuals who use mobile devices for tourism purposes, attachment to mobile devices increases the intention to use the devices (Kim et al. 2016c). Although attachment plays an important role in explaining consumers' behavior in digital tourism environments, it remains unclear what makes potential tourists attached to VR tourism content. In this respect, this study examines attachment to VR tourism as a critical factor among potential tourists in the SOR framework.

\section{Hypothesis Development}

Relationship between authentic experience and cognitive response. From a decision-making perspective, perceptions of authenticity influence desire in forming slow tourists' intention and travelers' behavioral intention to visit slow tourism destinations (Meng and Choi 2016a, 2016b). In cultural and religious events, perceived existential authenticity positively affects event satisfaction (Novello and Fernandez 2016), implying that authentic experience influences affective response because satisfaction is closely related to affective aspects. Moreover, from a cultural tourism perspective, perceived authenticity positively influences place satisfaction (Ramkissoon 2015). In travel and tourism contexts, authenticity is conceptualized as natural, exceptional, genuine, true, unique, original experiences (Chung et al. 2018; Kim, Bonn, and Lee 2017). Thus, this study operationalizes authentic experience with tourism-related VR activities with regard to genuine, exceptional, and unique aspects.

With regard to servicescapes, Bitner (1992) expands the SOR model by including cognitive responses in Mehrabian and Russell's (1974) original SOR theory. Cognitive response can be defined as people's beliefs about a place and their beliefs about the people 
and products found in that place. Thus, positive (negative) cognitions can lead to positive (negative) beliefs and attributions associated with an organization, its people, and its products (Bitner 1992). Lin and Wang (2012) conceptualize perceived value by considering quality, emotional response, monetary price, behavioral price, and reputation as cognitive variables in the context of travel products. Chang, Shu, and King (2014) evaluate utilitarian value using practicality, matching needs, convenience, and waiting for services as cognitive responses in travel environments. Kim et al. (2016a) assess perceived usefulness and time savings on mobile travel sites, and Kim, Bonn, and Lee (2017) measure the benefits and advantages of mobile travel social media as cognitive constructs. Therefore, this study operationalizes the cognitive response to tourism-related VR experiences using the concepts of benefits, usefulness, and advantages.

In a theme park's physical surroundings, novelty as a stimulus influences perceptions of utilitarian value as a cognitive response (Chang, Shu, and King 2014). It is assumed that authentic experience influences cognitive response because authenticity is directly associated with novelty in the context of tourism (Cohen 1988). Novelty as a stimulus influences cognitive response among festival attendees (Yoo, Lee, and Lee 2015). Additionally, the authenticity of ceramic souvenirs directly and positively affects cognitive response, such as purchasers' perceived value of these souvenirs (Lin and Wang 2012), suggesting that authentic experience may influence cognitive response to tourism-related VR experiences. Moreover, In the context of using technologies in tourism, consumers' authentic experiences with technologies have a positive effect on their behavioral intention (Kim, Bonn, and Lee 2017), implying that authentic experience influences cognition. In VR tourism settings, if platforms present the authenticity needed for the impending arrival of virtual tourism, users' perceived value of VR tours is increased (Yung and Khoo-Lattimore 2017). Thus, it is assumed that authentic experience is closely related to cognitive response. In association with 
the literature above, the current research postulates the following hypothesis for VR tourismrelated activities:

$H_{1}$ : Authentic experience has a positive effect on cognitive response to VR tourism experiences.

Relationship between authentic experience and affective response. Regarding the subconstructs of affective response, Venkatesh $(2000,351)$ defines enjoyment as "the extent to which the activity of using [a] specific system is perceived to be enjoyment in its own right aside from any performance consequence resulting from system use.” Van Der Heijden (2004) argues that enjoyment specifies the extent to which consumers receive entertainment from searching hedonic information technology systems. On mobile social media sites, enjoyment plays a significant role in better understanding users' behavior (Kim, Lee, and Bonn. 2017). Moreover, enjoyment has an important impact on online game players (Lowry et al. 2013) and plays a vital role in predicting VR consumers' behavioral intention to visit a destination (Huang et al. 2016). The effect of enjoyment on affective attitude change confirms VR tourism as hedonic experience (Tussyadiah et al. 2018). In particular, in virtual worlds, enjoyment is conceptualized as enjoyable, exciting, pleasant, and interesting characteristics (Guo and Barnes 2011). Grounded in the studies above, this research operationalizes an enjoyment construct with enjoyable, pleasurable, funny, and happy aspects as a sub-construct for affective response in the VR tourism context.

Emotional involvement, one of the sub-constructs, is defined as "the degree to which an individual is emotionally engaged in a behavior" (Holsapple and Wu 2007, 87). A study investigating hedonic consumption behaviors in a 3D multi-user virtual environment suggest that emotional involvement is one of the key factors in understanding user experience with regard to the entertainment nature of virtual worlds (Saeed, Yang, and Sinnappan 2009). In 
VR tourism, a greater perception of emotional involvement in experiencing a 3D tourism site is correlated with greater behavioral intention to visit the destination (Huang et al. 2013). The level of emotional involvement offered by a VR system is one factor that influences users' feelings of reality (Baños et al. 2004). Moreover, full emotional involvement, as a positive affective response, increases the perception that a VR experience is authentic, which in turn leads to the behavioral intention to visit the destination depicted in VR tourism (Guttentag 2010). In the context of VR travel and tourism activities, emotional involvement is conceptualized by feeling immersion, impressions, and association with travel and tourism activities (Huang et al. 2013). In this respect, this study operationalizes emotional involvement using involvement, impression, and empathy as a sub-construct for affective response in the VR tourism domain.

Nah et al. (2010) define flow theory "as [the] main theoretical foundation to understand and empirically assess the impact of flow on brand equity and behavioral intention in 3D virtual worlds" (277). Flow state is defined as "the holistic sensation that people feel when they act with total involvement" (Csikszentmihalyi 1975, 36) and has been described as the optimal experience. Flow state in 3D virtual worlds considerably influences learners' attitudes toward e-learning (Huang, Backman, and Backman 2010). Flow theory is a valuable tool to recognize individuals' experiences when navigating the second life, and flow state influences involvement and potential VR tourists' behavior (Huang, Backman, and Backman 2012). In VR tourism environments, flow state has significant effects on perceptions of easiness and the intention to travel as well as usability and behavioral intention to travel (Huang et al. 2013). In virtual travel communities, flow plays key roles in information quality, system quality, satisfaction, stickiness, and word-of-mouth (Gao, Bai, and Park 2017). In the context of digital tourism technologies, flow state is conceptualized as captivation, immersion, deep involvement, and a focus on the use of technologies (Kim, Lee, and Bonn 2017). Despite the 
importance of users' flow state in virtual tourism as a hedonic variable, research has not been conducted to understand VR tourists' continued use. Therefore, this study operationalizes flow state using the aspects of captivation, immersion, and absorption. Furthermore, this research measures affective response as a second-order factor that consists of enjoyment, emotional involvement, and flow state in VR tourism activities.

Virtual heritage is playful in its character, engaging in an authentic experience, which functions as a means for tourists to break free of the routines and constraints of everyday life (Dueholm and Smed 2014), which can lead to enjoyment. 3D-based digital cultural heritage suggests that a more pluralistic notion of authenticity is desirable for researching and understanding the changing conditions of both media art and archaeological cultural heritage (Muñoz Morcillo et al. 2017), which could result in visitors' emotional involvement. Because perceptions of authenticity are activated by experiences that involve all of the senses, the visual dimension is important in the experience of authenticity (Mura, Tavakoli, and Sharif 2017) and may influence potential tourists' flow state. In this sense, this study considers authentic experiences as the stimuli for affective responses to tourism-related VR experiences in relation to Mehrabian and Russell's (1974) SOR theory. Therefore, the current study postulates the following hypothesis for VR tourism by applying the SOR framework: $\mathrm{H}_{2}$ : Authentic experience has a positive effect on affective response to VR tourism experiences.

Relationships between cognitive response, affective response, attachment, and visit intention. Because developers of VR content aim to attract potential tourists to visit the destinations presented in the VR and to maintain users' attachment to VR content as regular patrons, this study regards attachment as a response and second outcome variable. In particular, as the theoretical justification for the outcome variable, the tourism literature suggests that 
attachment is formed by tourists' experiences (Gross and Brown 2008; Io and Wan 2018; Lalicic and Weismayer 2018; Oleksy and Wnuk 2017). For example, involvement in tourists' experiences (centrality to lifestyle and food/wine) has been found to have a positive and significant effect on place attachment to South Australian tourist destinations (Gross and Brown 2008). Furthermore, activity-based tourism experiences have been found to influence place attachment to casino resorts (Io and Wan 2018). In addition, tourists' experiences that are enhanced by the use of mobile devices while travelling contribute to tourists' attachment to mobile devices (Lalicic and Weismayer 2018). In location-based augmented reality games, players' satisfaction and social contact with other players lead to their attachment to the gaming place (Oleksy and Wnuk 2017). From the perspectives of VR and digital tourism technology, this study employs the first-order factor with multiple items to measure the attachment construct based on Kim et al. (2015, 2016b, 2016c), Oleksy and Wnuk (2017), and Tussyadiah (2016). Specifically, the four items of attachment to tourism-related VR experiences in this study include cognitive and affective characteristics, such as function, connection, emotional engagement, and psychological identity.

In the context of a comprehensive evaluation of restaurant quality, Jang and Namkung (2009) conceptualize behavioral intention as visit intention, including returning to a place, recommending the place to friends, and saying positive things about the place. In travel- and tourism-related VR activities, Huang et al. (2013) evaluate behavioral intention as obtaining more information, interest in visiting, revisit intention, and recommending VR activities. From the VR tourism perspective, visit intention is measured by targeting the behavioral intention to visit the destination in the future, which has been validated in previous studies on tourists' intention to visit or revisit a destination in the future (Tussyadiah et al. 2018). Therefore, this study operationalizes visit intention with intention, planning, and willingness to visit the destination shown in VR tourism. 
In the context of emotion and adoption, cognitive response has an effect on affective response (Lazarus 1991). The SOR framework suggests that customers' cognitive response contributes to their emotional response to the restaurant servicescape (Kim and Moon 2009). The extended SOR framework argues that in website environments, the greater the perceived risk of shopping at the online retailer, the more negative consumers' emotion is toward the online retailer (Kim and Lennon 2013). With regard to virtual communities, the cognitive aspects of functional usefulness and system quality lead to attitudes toward these communities (Gupta and Kim 2007), implying that cognitive response is associated with affective response. More importantly, among VR tourists, a sense of presence during VR experience has a positive effect on the enjoyment of the VR experience (Tussyadiah et al. 2018), and it is assumed that cognitive response influences affective response in the context of tourismrelated VR activities.

Using an extended SOR model, this study adds attachment to VR tourism in addition to visit intention. From the perspective of digital tourism technologies, cognitive response is related to attachment and visit intention. Specifically, the value of tourism products on groupbuying websites (e.g., cognitive response) significantly and positively influences buyers' attachment to the websites (Kim et al. 2015). Additionally, timesaving on mobile sites (i.e., cognitive response) significantly and positively influences attachment to the websites for tourism shopping (Kim et al. 2016b). Among users of online social networking services, social capital as a cognitive response leads to attachments of common bonds and identity on online social networking sites for travel (Kim, Lee, and Bonn 2016; Kim, Lee, and Preis 2016), implying that cognitive response is closely associated with attachment. Moreover, because the integrated use of mobile phones enhances tourists' experiences, the perceived socialness of the mobile phone (cognitive response) significantly affects attachment to the mobile phone while travelling (Lalicic and Weismayer 2018). In location-based augmented 
reality games, satisfaction with playing and social relations predicts attachment to the place (Oleksy and Wnuk 2017), suggesting that cognitive response influences attachment.

Based on the understanding of servicescapes in the SOR theory, positive cognitions may produce more positive beliefs and attitudes associated with a company, its employees, and its services, resulting in behaviors (Bitner 1992). Furthermore, the perceived service quality of consumers as a cognitive response significantly affects consumers' revisit intention in a theme restaurant (Kim and Moon 2009). Based on an extended SOR model, the lesser the perceived risk of buying at an Internet shop (i.e., cognitive response), the greater consumers' buying intention is in relation to the Internet shop (Kim and Lennon 2013). According to the SOR model, visitors' utilitarian values of cognitive responses influence revisit behaviors among theme park visitors (Chang, Shu, and King 2014). In VR tourism activities, potential tourists' perceived usefulness (cognitive response) has a positive effect on their behavioral intention to visit a place in VR activity (Huang et al. 2013, 2016). For cultural heritage sites, value cocreation through the application of VR technology enhances visitors' experience, creating positive word of mouth and revisit intention (Jung and tom Dieck 2017). A positive attitude toward the use of VR in the tourism context involves full immersion in the experience, which in turn influences the behavioral intention to visit the destination in the future (Jung et al. 2017). In accordance with the literature, this study suggests that cognitive responses to VR tourism experiences are positively related to affective response, attachment to VR tourism experiences, and intention to visit the destination portrayed in the VR tourism experience. Hence, the current research postulates the following three hypotheses:

$H_{3}$ : Cognitive response has a positive effect on affective response to VR tourism experiences. $H_{4}$ : Cognitive response has a positive effect on attachment to VR tourism experiences. $H_{5}$ : Cognitive response has a positive effect on visit intention to the destination depicted in the VR tourism experience. 
Relationships between affective response, attachment, and visit intention. Affect, as the full gamut of relevant emotions, includes such diverse feelings as love, hate, fear, joy, boredom, anxiety, pride, anger, disgust, sadness, sympathy, lust, ecstasy, greed, guilt, elation, shame, and awe (Holbrook and Hirschman 1982). Service establishments may orchestrate affective content through skills, engagement, emotions, and a dramatic sense of service providers (Arnould and Price 1993). A positive affective response of enjoyment, emotional involvement, and flow state can be associated with attachment to tourism-related VR experiences and behavioral intention to visit the destination in VR tourism contexts. Accordingly, the construct of affective response to tourism-related VR experiences in this study includes enjoyment, emotional involvement, and flow state as a second-order factor as well as a reflective measure within the research model.

Because enjoyment represents a main cause of attachment in close associations (Bowlby 1951), it is anticipated that the more enjoyable an affective response is, the more closely it is associated with attachment. Because store-evoked pleasure and arousal are closely associated with brand attachment (Orth, Limon, and Rose 2010), it is assumed that affective response positively influences attachment. Enjoyment of mobile tourism sites significantly influences attachment to the sites (Kim et al. 2016b), implying that the greater the level of enjoyment as an affective response, the more closely it is related to attachment. Modern tourists' affective feelings derived from mobile phone usage enhanced by effective travel-related applications encourage them to be attached to the mobile phone while travelling (Lalicic and Weismayer 2018). Among Pokémon Go players, excitement as an affective appraisal highly predicts active place attachment to the location-based augmented reality game (Oleksy and Wnuk 2017), implying that affective response influences attachment. 
The SOR theory explains organisms' affective responses (i.e., emotions), which lead to individuals' behavior of avoiding or accessing specific surroundings (Bitner 1992; Mehrabian and Russel 1974). In a theme restaurant setting, customers' sense of pleasure as an affective response is positively related to revisit intention (Kim and Moon 2009). Additionally, hotel guests' emotional response significantly influences their loyalty to the hotel (Jani and Han 2015). In an extended SOR model, restaurant customers' affective responses positively influence behavioral intention (Jang and Namkung 2009). The more positive shoppers' affection is while purchasing at an online shop, the higher their purchase intention is toward that online shop (Kim and Lennon 2013). From a tourism-related perspective, emotions (pleasure, attractiveness, excitement, interest, fun, and satisfaction) influence behavioral intention (Chang, Shu, and King 2014). In VR tourism, emotional involvement, positive emotions, and flow state have positive impacts on the behavioral intention to travel (Huang et al. 2013). With regard to tourists' use of VR applications, immersive and involved experiences appear to affect their intention to visit a destination in VR applications (Jung et al. 2017). With regard to the use of VR and augmented reality in the context of museums, entertainment experience has a significant influence on tourists' intention to revisit museums (Jung et al. 2016). In accordance with the literature above, this research assumes that the affective response to tourism-related VR experiences is significantly related to attachment to VR tourism experiences and visit intention to the place depicted in the VR tourism experience. Thus, the following two hypotheses are suggested:

$H_{6}$ : Affective response has a positive effect on attachment to VR tourism experiences.

$H_{7}:$ Affective response has a positive effect on visit intention to the destination depicted in the VR tourism experience. 
Relationship between attachment and visit intention. Attachment to a tourism destination is suggested as one of the key determinants of behavioral intention (Ramkissoon 2015). Scholars and tourism marketers have shown interest in building an integrated model of attachment to tourism destinations and studying its link to behavioral intention (e.g., Prayag and Ryan 2012; Ramkissoon, Graham Smith, and Weiler 2013; Veasna, Wu, and Huang 2013). In digital tourism contexts, attachment is one of the key predictors of behavioral intention. Attachment to a mobile tourism shopping site has a positive effect on continued usage of the site in the context of the dual route of persuasive communications (Kim et al. 2016a). With regard to smartphone users, site, group, and interpersonal attachment to mobile tourism websites positively influence reciprocal altruism among users of these sites (Kim et al. 2016b). Attachment to mobile devices positively influences behavioral intention of mobile device usage in relation to tourism among smartphone and tablet owners (Kim et al. 2016c). Passion toward the mobile phone while travelling has a strengthening effect on positive affective feelings (Lalicic and Weismayer 2018), implying that tourists' attachment to digital technologies at destinations can lead to their visit intention to these destinations. In virtual worlds, when the level of place attachment (i.e., attachment to the virtual space) increases, individuals are more likely to revisit these places for similar experiences due to the interactional potential of similar places, which influences their intention to return (Goel et al. 2011). Virtual community attachment plays a more important role in explaining citizenship behaviors directed toward the virtual community than does satisfaction, which plays a significant role in explaining citizenship behaviors toward individuals (Chiu, Fang, and Wang 2015). In line with the literature review above, it is expected that attachment to VR tourism is a predictor of potential tourists' intention to visit a destination shown in VR tourism. Therefore, the following hypothesis is proposed: 
$H_{8}:$ Attachment to VR tourism has a positive effect on visit intention to the destination depicted in the VR tourism experience.

Based on the hypotheses above, this study postulates the proposed research model shown in Figure 2. The model explains the structural relationships among authentic experience, cognitive and affective responses, attachment to VR tourism, and visit intention among VR tourists by applying the extended SOR paradigm.

\section{Insert Figure 2 here}

\section{Methods}

\section{Measurements}

To avoid measurement inaccuracies related to single items, previously validated multimeasurement items for the questionnaire were utilized (Churchill 1979) after they were adapted to this study's context. The survey questionnaire in this study initially included 27 items and seven constructs: authentic experience, cognitive response, enjoyment, emotional involvement, flow state, attachment to VR, and visit intention in VR tourism settings.

Authentic experience in tourism-related VR activities was assessed with four items derived from previous studies by Chung et al. (2018), Gilmore and Pine (2007), Kim, Bonn, and Lee (2017), and Meng and Choi (2016a, 2016b) (e.g., "Using the tourism-related VR activity provided me with genuine experiences"). Cognitive response to tourism-related VR experiences was assessed with four items drawn from prior literature (Chang, Shu, and King 2014; Kim, Bonn, and Lee 2017; Kim et al. 2016a; Lin and Wang 2012) (e.g., "I gain knowledge from using the tourism-related VR activity"). Enjoyment of tourism-related VR experiences was assessed using four items derived from Guo and Barnes (2011), Huang et al. 
(2013, 2016), Tussyadiah et al. (2018), and Venkatesh (2000) (e.g., "Using the tourismrelated VR activity is enjoyable for me"). To assess emotional involvement in tourism-related VR experiences, four items were adapted from research conducted by Holsapple and Wu (2007), Huang et al. (2013), and Saeed, Yang, and Sinnappan (2009) (e.g., "I am completely involved in the tourism-related VR activity"). Four items were adapted from prior research (Csikszentmihalyi 1975; Huang, Backman, and Backman 2010, 2012; Huang et al. 2013; Kim, Lee, and Bonn 2017; Nah et al. 2010) to measure flow state in tourism-related VR experiences (e.g., "When I am using the tourism-related VR activity, I feel totally captivated"). To measure potential tourists' attachment to tourism-related VR experiences, four items were drawn from previous research (Kim et al. 2015, 2016b, 2016c; Oleksy and Wnuk 2017; Tussyadiah 2016) (e.g., "I am closely related to the content when using the tourism-related VR activity"). To assess visit intention to the destinations in VR tourism activities, three items were drawn from previous research by Huang et al. (2013), Jang and Namkung (2009), and Tussyadiah et al. (2018) (e.g., "I am planning to visit the place that I observed in the tourismrelated VR activity").

Because 7-point Likert scales offer high reliability and discriminant validity according to Cicchetti, Showalter, and Tyrer (1985) and Preston and Colman (2000), a total of 27 items were appraised on a 7-point Likert-type scale ranging from (1) strongly disagree to (7) strongly agree. In addition, five items associated with VR tourism (length of experience, time spent, primary motivation, visiting the destination, and frequency of accessing) were used based on the literature (Kim et al. 2016c). Six questions related to socio-demographics (i.e., age, gender, educational level, monthly household income, occupation, and marital status) were also included.

The measurement was originally designed in English and then translated into Korean by two professionals who are proficient in English and Korean. The Korean measurement was 
then back-translated into English, and some discrepancies were remedied between English and Korean expressions (Brislin 1970). Three scholars who were experts in the study topic evaluated the content validity of the survey questions. In addition, three practitioners of VR technology were asked to evaluate whether the questionnaire appropriately assessed VR tourists' behaviors. Based on these processes, of the items initially generated from the literature, one item on emotional involvement was deleted because of overlapping meaning (i.e., "I am completely engaged in the VR content for tourism-related activities"). Additionally,

one item for visit intention was added to the questionnaire (e.g., "I intend to invest money and time to visit the place that I observed in the VR tourism"). As a pilot test, the questionnaire was administered to five graduate students who majored in tourism. Several items on authentic experience, attachment to VR, and visit intention were reworded according to their comments. A pretest was administered to 50 students who had engaged in VR tourism within the past year. This procedure resulted in further revision of some ambiguous items on affective response (i.e., enjoyment, emotional involvement, and flow state) to ensure clarity. The modified questionnaire was used for the final survey.

\section{Data Collection}

The ability of today's online consumers to respond quickly and cost effectively to the Internet has enabled researchers to examine topics of interest through online surveys (Evans and Mathur 2005; Ilieva, Baron, and Healey 2002; Wright 2005). Because this study investigates specific consumer behavior in VR tourism, online surveys are considered particularly appropriate for use as data collection methods (Huang et al. 2013, 2016). The subjects in the current research were Koreans who were 19 years old or over and who had experience with VR tourism within the prior year. Drawing on data provided by the Korea Internet Security Agency (2017) regarding mobile Internet users, a quota sampling method was employed 
according to the VR users' age and gender.

Macromill Embrain (www.embrain.com), an online survey company with Asia's largest panel of 3 million panelists as of February 2018 (Embrain 2018), was hired to collect samples for the study. This online survey company was selected for its rigorous sampling procedures and systems developed by the company. It strictly adheres to consumer sample selection to ensure the quality of the data. Specifically, the survey company first used panel registration numbers to compare and verify personal information on the respondents. The respondents' identities were verified using individuals' legitimate names and panel-membership identifications. Second, surveys completed too quickly or repeatedly were identified and removed by the system. Third, responses from respondents who were not qualified by the screening question for participation in the research were removed. Fourth, to reduce response bias, the multiple-choice items were rotated so that each respondent had a different order of questions. Finally, respondents were asked to present the name of the VR tourism content that they had most recently experienced. For all following questions, the name of the VR content stated by the respondent was represented on each question of the questionnaire.

Data collection through the online survey was performed from October 30 to November 25, 2017. An invitation was designed for research participation with information about the purpose of the research and the security of personal information. Invitations were sent via email to 5,813 subjects based on a random sampling of $1,200,000$ consumer databases of the survey company in Korea. Of 2,034 respondents who opened the email invitation, 1,756 respondents linked to the Internet invitation. In a screening question purposely designed for this survey, all subjects were asked to indicate whether they had experienced VR tourism in the previous year (i.e., "In the past 12 months, have you had any experience with tourismrelated VR activities?"). Before the screening question on the first page of the questionnaire, we provided the definition and category of tourism-related VR activities. For example, in this 
survey, the term "tourism-related VR activities" referred to the use of VR devices to play, enjoy, experience, travel, and explore information by looking at pictures, gaming, watching 3D 360-degree videos, watching drone videos, looking at holographic images, and other tourism-related activities. Additionally, in this survey, the categories of tourism-related activities were any of the following: leisure activities and movies, amusements and games, overseas or domestic travel, space and underwater tours, exhibitions and entertainments, festivals and events, sports and expos, resorts and cruises, and recreation and theme parks. Only 753 panelists who responded "yes" to this question were eligible to complete the survey. Of these, 408 respondents completed the questionnaire as a valid sample. There were no outliers or omitted answers (Hair et al. 2010), so all 408 cases were utilized for the analysis, representing a 54.2\% response rate based on the American Association for Public Opinion Research $(2016,58)$.

\section{Data Analysis}

The research employed partial least squares-structural equation modeling (PLS-SEM) analysis to examine the proposed theoretical framework and hypotheses for the following reasons. First, unlike traditional covariance-based SEM analyses, PLS-SEM requires minimal criteria for measurement scales, sample size, and residual distributions to validate a model with bootstrap re-sampling method as a non-parametric approach (Chin, Marcolin, and Newsted 2003). Second, PLS-SEM can analyze both reflective and formative indicators with secondorder factors simultaneously within a model (Chin 1998). Third, PLS-SEM has been suggested to be more appropriate for complicated models or multi-group analysis than traditional SEMs (Hair et al. 2012). Thus, in this study, SmartPLS 3.2.7 was used to analyze the measurement model as well as the structural model (Ringle, Wende, and Becker 2015).

Because respondents were asked to rate all survey questions at once, common method 
variance was a potential issue. Thus, precautions were taken using several procedural remedies to address common method bias (Conway and Lance 2010; Podsakoff et al. 2003). First, the introduction section of the questionnaire included a description of the study's purpose followed by a statement assuring the anonymity of all respondents. Second, to decrease respondent apprehension, the survey instructions noted that there were no right or wrong answers to the questions. Third, the definitions of important concepts (e.g., VR usage for tourism-related activities, tourism-related content) were clearly explained at the beginning of the survey to help ensure response validity. Fourth, the questionnaire consisted of three sections: the first section included information about VR activities, the second section included measurement items related to the research model, and the third section included personal questions about demographic characteristics. Fifth, the orders of scale items were randomly rotated for each respondent to reduce response bias.

Harman's single-factor test as a post hoc statistical test was performed to confirm whether common method bias was present in the resultant data set (Harman 1967). We subjected all self-reported survey items to exploratory factor analysis (EFA). In this process, when a single factor appears or when one factor accounts for more than $50 \%$ of the variance of the variable, there is an issue of common method bias (Podsakoff et al. 2003). The EFA results revealed that six variables were delineated (eigenvalue $>1$ ), representing $77.3 \%$ of all factors, including the first factor (48.3\%) and subsequent factors $(9.5 \%, 5.7 \%, 5.0 \%, 4.8 \%$, and $3.9 \%)$. Because the single-factor test has been found to have some limitations (Chin, Thatcher, and Wright 2012), a marker variable approach was also employed. For this procedure, a PLS algorithm was applied. A marker variable (negative emotional response to VR tourism experience) was used to assess the correlations of all theoretical constructs in the PLS-SEM framework. The corrections of the marker variable with the seven constructs of the research frame were authentic experience (-0.050), cognitive response (-0.102), enjoyment (-0.234), emotional 
involvement (-0.108), flow state (-0.114), attachment to VR (-0.052), and visit intention ($0.123)$. The resultant average of the squared multiple corrections with the marker variable was 0.016 for the theoretical constructs, which is small and insignificant (Lindell and Whitney 2001). Accordingly, both the traditional single-factor test and the marker-variable method indicated that common method variance was not an issue in the study.

\section{Second-order factor model}

Second-order models are most commonly applied in the context of research where the measurement tool evaluates several related constructs measured from multiple items (Chin 1998). The second-order model represents the hypothesis that these seemingly distinct but related constructs can be accounted for by one or more common underlying higher-order constructs (Chen, Sousa, and West 2009). In comparison to first-order models with correlated factors, second-order factor models can provide a more parsimonious and interpretable model when researchers hypothesize that higher-order factors underlie their data (Chen, Sousa, and West 2009). There are two unique characteristics of the second-order model with reflective indicators: first, the second-order factor becomes the exogenous construct, whereas the firstorder factors are endogenous; second, there are no indicators of the second-order factor (Narayan, Rajendran, and Sai 2008). This is accomplished through the specification of a second-order factor model that posits that the first-order factors estimated are actually subdimensions of a broader and more encompassing second-order factor (Hair et al. 2010), which, in this case, is affective response. Therefore, based on the literature review above, this study creates affective response as a second-order construct using the three sub-constructs of enjoyment, emotional involvement, and flow state.

\section{Results}




\section{Profile of the Sample}

Half of the respondents in the sample were female (50.2\%), and a quarter were in the $40-49$ age bracket (26.2\%). The majority of respondents attended university or had a university degree $(68.2 \%)$ and were single (62.6\%). More than a third of the participants were office workers (41.9\%) and earned KRW (Korean won) 4.00 - 5.99 million in monthly household income $(35.5 \%)$ (US\$1 is equivalent to KRW1,065). Almost half of the participants had experienced VR tourism from 6 to 12 months earlier (48.2\%) and spent 10 to 29 minutes per experience on VR tourism (57.6\%). The respondents' main motivation to use VR tourism was playing (53.0\%), and half of the participants experienced VR tourism once a year or more (55.0\%). Furthermore, $36.8 \%$ of the sample visited destinations in VR tourism.

\section{Measurement Model}

By employing component-based PLS-SEM, the convergent and discriminant validity of 27 indicators were examined (Bhattacherjee and Sanford 2006). Both convergent and discriminant validity were confirmed because every factor loading exceeded 0.5 and no items of any construct shared high levels of residual variance with other constructs, except one item on flow state (Table 1). Next, the measurement tool was evaluated to validate the reliability, convergent, and discriminant validity of the structure (Tables 1 and 2). Specifically, all constructs were deemed reliable because their Cronbach's alphas (Campbell and Fiske 1959) and composite reliability levels were all higher than 0.70 (Hair et al. 2010). All constructs of convergent validity were deemed acceptable according to Fornell and Larcker (1981) because their average variance extracted (AVE) was higher than 0.50 .

\section{Insert Tables 1 and 2 here}


Finally, discriminant validity is established on the basis of the heterotrait-monotrait ratio of correlations (HTMT), a procedure superior to the commonly considered Fornell-Larker (1981) criterion and assessments of cross-loadings (Ahrholdt, Gudergan, and Ringle 2017; Henseler, Ringle, and Sarstedt 2015). The results show that all HTMT values of the latent variables were below the critical and conservative value of 0.85 (Table 2 ). The sub-constructs [enjoyment $(\lambda=0.904, \mathrm{t}$-value $=78.331, \mathrm{p}<0.001)$; emotional involvement $(\lambda=0.862$, $\mathrm{t}$ value $=53.062, \mathrm{p}<0.001)$; flow state $(\lambda=0.808 \mathrm{t}$-value $=30.480, \mathrm{p}<0.001)]$ significantly exceeded the minimum requirement of factor loadings (0.5). Based on do Valle and Assaker's (2016) suggestion, the effect size of each endogenous variable was tested using the f square and q square. As shown in Table 2, all values for the effect size of $\mathrm{f}^{2}$ fell between 4.431 and 0.198 , which are greater than the medium effect size (e.g., large $=0.35$, medium $=0.15$, small $=0.02)$ (Cohen 1992). Additionally, all values for the effect size of $\mathrm{q}^{2}$ fell between 0.645 and 0.189 , which are greater than the medium effect size.

\section{Structural Model}

To test the research model, bootstrapping with 1,000 sub-samples was employed to analyze the relational assessments and the hypotheses by t-statistics using PLS-SEM because the data were not sufficient for the criterion of multivariate normality (Hair et al. 2012). Specifically, we tested skewness and kurtosis for all items of the seven constructs. Some items of the constructs (i.e., one each from enjoyment and flow state) revealed a non-normal distribution, so we conducted bias-corrected and accelerated bootstrapping, which corrected the bias of our non-normal data (Efron 1987). To estimate the accuracy of the structural framework, the $\mathrm{R}^{2} \mathrm{~s}$ of explained variance for cognitive response (27.5\%), affective response (54.4\%), enjoyment (81.7\%), emotional involvement (74.4\%), flow state (65.1\%), attachment to VR (47.8\%), and visit intention (43.5\%) were calculated as predictive power (Hair et al. 2010). 
As shown in Figure 3, all eight hypotheses were supported. Specifically, authentic experience was found to significantly influence cognitive response $\left(\mathrm{H}_{1}: \gamma=0.524\right.$, $\mathrm{t}$-value $=$ 10.573, $\mathrm{p}<0.001$ ), which was the strongest effect among VR tourists in the proposed research model. Additionally, authentic experience was found to positively influence affective response $\left(\mathrm{H}_{2}: \mathrm{\gamma}=0.521, \mathrm{t}\right.$-value $\left.=11.201, \mathrm{p}<0.001\right)$, which was the second strongest effect from the SOR theory in the research model. Cognitive response significantly affected affective response $\left(\mathrm{H}_{3} \beta=0.316, \mathrm{t}\right.$-value $\left.=6.715, \mathrm{p}<0.001\right)$, attachment to $\mathrm{VR}\left(\mathrm{H}_{4} \beta=0.387\right.$, $\mathrm{t}$-value $=7.928, \mathrm{p}<0.001)$, and visit intention $\left(\mathrm{H}_{5} \beta=0.308, \mathrm{t}\right.$-value $\left.=5.173, \mathrm{p}<0.001\right)$. Affective response significantly influenced attachment to $\operatorname{VR}\left(\mathrm{H}_{6} \beta=0.389\right.$, t-value $=8.183$, $\mathrm{p}<0.001)$ and visit intention $\left(\mathrm{H}_{7} \beta=0.159\right.$, $\mathrm{t}$-value $\left.=2.352, \mathrm{p}<0.05\right)$. Visit intention was significantly affected by attachment to VR $\left(\mathrm{H}_{8} \beta=0.295\right.$, $\mathrm{t}$-value $\left.=5.427, \mathrm{p}<0.001\right)$.

The multicollinearity of each independent variable was diagnosed using the variance inflation factor (VIF). Because all values for VIF fell between 1.634 and 5.021, multicollinearity was not an issue in this research (Hair et al. 2010; Hair et al. 2012).

\section{Insert Figure 3 here}

\section{Mediating Effects}

Additional analysis of the mediating roles of cognitive response, affective response, and attachment to VR was performed to investigate whether they functioned as mediators within the research framework. The PLS bootstrapping method using 1,000 sub-samples was applied to examine the relationships between authentic experience and attachment to VR, authentic experience and visit intention, cognitive response and visit intention, and affective response and visit intention. As shown in Table 3, authentic experience had significantly positive indirect effects on affective response to VR tourism experiences $(\mathrm{\gamma}=0.166, \mathrm{t}$-value $=5.194, \mathrm{p}$ 
$<0.001)$, attachment to $\operatorname{VR}(\mathrm{\gamma}=0.470, \mathrm{t}$-value $=13.303, \mathrm{p}<0.001)$, and visit intention $(\mathrm{\gamma}=$ $0.409, \mathrm{t}$-value $=10.201, \mathrm{p}<0.001)$. Additionally, cognitive response had a significant and positive indirect influence on attachment to $\operatorname{VR}(\beta=0.123$, t-value $=4.894, \mathrm{p}<0.001)$ and potential visitors' intention to visit the destination in VR $(\beta=0.201$, t-value $=6.333, \mathrm{p}<$ 0.001). Furthermore, affective response had a significantly positive indirect influence on VR tourists' intention to visit the destination $(\beta=0.115$, t-value $=4.361, \mathrm{p}<0.001)$. Thus, cognitive response, affective response, and attachment to VR played significant mediating roles in the model.

\section{Insert Table 3 here}

\section{Inclusion of Control Variables}

To determine whether there were demographic influences on the research model, this study tested gender, age, marital status, education, and income as control variables using 1,000 bootstrap resamples of PLS-SEM. This analysis confirmed the additional variable bias and verified the research model. Specifically, the five demographic variables were controlled to provide a precise assessment of the relationship between affective response and visit intention. Figure 4 shows the hypotheses of the research model with the control variables. The control variables were included to test whether the research hypotheses were supported when the impact of the control variables was considered. The results indicate that when the analysis variables were included, the analytical data supported the seven hypotheses. These results support the argument that gender, age, education, marital status, and income control variables are not biased toward the current outcomes. 


\section{Conclusion and Implications}

Along with the rapid advancement of digital technology, VR is an emerging area in the fourth industrial revolution. In particular, VR provides an opportunity for tourists to experience a destination in advance, which is an effective marketing strategy for destination marketing organizations. More importantly, VR tourism offers potential tourists the opportunity to visit the destination presented in VR. However, studies on VR tourism have not examined the important factors and how to make potential tourists visit the locations presented in VR tourism activities. To bridge this gap, this research primarily identified which factors encourage potential tourists to visit the destinations presented in VR activities from the perspectives of authentic experience with tourism-related VR activities and attachment to VR tourism experiences. This study examined VR tourists' stimulus, responses, and behavioral intention using the SOR theory. Accordingly, this research developed and tested a theoretical framework for the relationships among authentic experience (stimulus), cognitive and affective responses (organism), attachment to VR, and visit intention to the destination in the VR content using the SOR paradigm. In particular, to better capture the comprehensive meaning, this study operationalized affective response to tourism-related VR experiences as a second-order factor and reflective measure that consisted of enjoyment, involvement, and flow state.

The results revealed the highly significant impact of consumers' authentic experience on their cognitive and affective responses to VR tourism experiences, indicating that authentic experience with tourism-related VR activities is one of the key factors in the commercialization of VR. Moreover, consumers' cognitive response to tourism-related VR activities contributes to their affective response to VR tourism experiences. Additionally, this study identified potential visitors' cognitive and affective responses to VR tourism experiences as significant mediators in predicting attachment to VR tourism experiences and 
visit intention to the destination presented in VR. The results further demonstrated that consumers' intention to visit the destination shown in the VR tourism content was influenced by their attachment to VR tourism experiences. In addition, the results suggest that affective responses to tourism-related VR experiences fundamentally consisted of enjoyment, emotional involvement, and flow state. This study sheds light on why potential tourists want to visit the destinations shown in VR tourism activities and provides implications for academics and practitioners.

\section{Theoretical Implications}

Despite the growing importance of VR tourism in destinations, research on the factors that influence VR tourists' behavior and potential tourists' stimulus and response is scarce. This study provides academics with useful insights for theory formation and verification of the SOR paradigm. Specifically, the results of this study offer a number of theoretical contributions to academia and researchers. For example, the current research validated the utility of the extended SOR framework with the inclusion of authentic experience to tourismrelated VR activities as a stimulus and attachment to VR as a response within the VR tourism setting. Moreover, this research theoretically validated that the extended SOR model can include affective response to VR tourism experiences as a second-order factor and a reflective measure consisting of enjoyment, emotional involvement, and flow state among VR tourists.

The most theoretically important finding is that cognitive response to VR tourism experiences has a greater effect on potential tourists' visit intention to attractions presented in VR tourism-related content than affective response or attachment to VR. That is, a potential tourist is more likely to intend to visit a place that was presented in VR tourism activities when the tourist thinks the VR is beneficial. More interestingly, affective response to VR tourism experiences has a greater impact on attachment to VR than intention to visit the place shown in VR tourism. This result implies that consumers are more likely to be attached to VR 
tourism content than to visit the destination displayed in the VR tourism content when they are enjoying, emotionally involved in and captivated by VR tourism activities.

Specifically, the finding of the highly significant effect of authentic experience on cognitive response contributes to the literature, extending previous studies on the relation between authenticity and cognition (e.g., Kim, Bonn, and Lee 2017; Yung and KhooLattimore 2017). Additionally, the strong relationship between authentic experience and affective response in this study theoretically demonstrates that VR tourism content is closely related to the emotional immersive experience and substantially extends the findings of previous studies (e.g., Dueholm and Smed 2014; Muñoz Morcillo et al. 2017; Mura, Tavakoli, and Sharif 2017). The result of the significant effect of cognitive response on affective response elucidates the theoretical relation between cognition and affection, extending previous studies of virtual communities (Gupta and Kim 2007) and VR tourism (Tussyadiah et al. 2018). Furthermore, this research found an important association between cognitive response and attachment to VR that provides a tremendous opportunity for theory building, extending the findings of former research (e.g., Lalicic and Weismayer 2018; Oleksy and Wnuk 2017). Cognitive response has a highly significant effect on visit intention and provides a new starting point for VR research that will considerably broaden or extend previous studies (e.g., Huang et al. 2013, 2016; Jung and tom Dieck 2017; Jung et al. 2017).

This research demonstrates that affective response largely influenced attachment to VR tourism, providing implications for academia as well as broadening prior studies (e.g., Lalicic and Weismayer 2018; Oleksy and Wnuk 2017). Additionally, it was found that affective response had an effect on visit intention, providing insights for researchers and expanding previous literature (e.g., Jung et al. 2016, 2017). Furthermore, the results showed that potential tourists' intention to visit the destinations shown in VR content was positively influenced by their attachment to VR tourism, offering an innovative empirical testing of VR 
and strengthening prior theory (e.g., Chiu, Fang, and Wang 2015; Goel et al. 2011; Lalicic and Weismayer 2018). Noticeably, visit intention to destinations shown in VR was substantially influenced by cognitive response, whereas attachment to VR was significantly influenced by affective response, providing insightful implications for academia. Thus, this research provides a better understanding of potential tourists based on a theoretical framework of stimulus, process, and behavior toward VR tourism destinations.

More importantly, given the growing importance of VR tourism experiences, studies on both cognitive response and affective response are limited. In this respect, this study provides academics with useful insights for theory formation and verification in terms of cognitive and affective characteristics. The results of this research offer several theoretical contributions to the literature with the following summary. First, the current research validated the utility of both the cognitive and affective frameworks in VR tourism activity settings. Second, this research theoretically validated that the cognitive response can be an important factor for potential tourists visiting the destination shown in VR content. Third, given the considerable impact of enjoyment, emotional involvement, and flow state of the sub-constructs, this study provides theoretical insights on affective response as a key second-order factor for consumers using tourism-related VR activities to be attached to VR content.

\section{Practical Implications}

The findings suggest that VR tourism content producers should focus on creating authentic VR content because authentic experience with tourism-related VR activities was found to significantly impact the cognitive and affective responses of potential tourists. That is, VR content producers could design their content to have genuine and unique elements so that consumers obtain authentic experiences from VR tourism activities. Given that the relationship between authentic experience and affective response to VR activities is stronger 
than the relationship between authentic experience and cognitive response, VR tourism developers may boost the emotional factors of enjoyment, emotional involvement, and flow state with animations. In other words, developers can highlight VR tourism-related programs to be pleasurable, fun, involving, impressive, and captivating by stressing gamification.

According to the findings of this research, tourism destination marketing practitioners should pay attention to cognitive response if they want potential tourists to have an affective response, be attached to VR, and have intention to visit attractions presented in VR tourism. For example, tourism businesses could promote their VR products as knowledgeable, useful, and beneficial activities through online/mobile social media and websites so that potential tourists can obtain affective responses, attachment to VR experiences, and the intention to visit the destination in VR tourism activities. In addition, the results of this study suggest that destination marketers should make efforts to create VR content that includes hedonic elements so that potential tourists can be attached to and have intention to visit the destination shown in VR. For instance, destination marketers can augment sensory components of their VR content with audio, video and haptics along with artificial intelligence so that potential tourists can be emotionally immersed in and fascinated by the dynamic VR destination.

The impact of attachment to VR was found to be significant for potential tourists' intention to visit the place presented in VR. It is recommended that tourism marketers encourage users' attachment to VR by providing content that is closely related and important to potential tourists. In other words, tourism stakeholders could help to increase customers' attachment to tourism-related VR activities as an important part of their life by incorporating game characters. By doing so, practitioners can make potential tourists actually visit the destination presented in VR tourism. More importantly, VR tourists' visit intention was influenced by cognitive response more than by affective response. Therefore, commercial sectors should concentrate on cognitive aspects by including educational knowledge, cultural 
singularity, historical background, and practical information about VR destinations. This could be accomplished by tourism marketers' promotion of the benefits of VR tourism activities that encourage people to visit destinations viewed in VR tourism.

In particular, a stronger influence of affective response via attachment to VR leads to greater visit intention than the direct influence of affective response on visit intention. Consequently, VR platforms and devices should be developed to provide pleasurable experiences of VR tourism activities to promote consumer attachment, which increases potential tourists' visit intention. In other words, destination managers need to design applications with VR technologies to stimulate potential visitors' playfulness and passion. In addition, enjoyment from the sub-constructs is the most significant element for affective response in the second-order factor. Accordingly, VR tourism content should be created to offer amusement and happiness. This can be accomplished by developing exciting programs for VR tourism activities by including vivid 3D characters, applying popular animations, and presenting celebrities. Furthermore, destination marketers should utilize VR tourism content as tourism marketing and promotion tools for their future customers by combining three aspects of VR tourists' characteristics, cognition, affection, and attachment. In other words, tourism destination organizations and policy makers could develop a comprehensive VR advertising strategy for destination marketing tools that incorporates beneficial, enjoyable, and affective activities for their destinations. Specifically, destination marketing strategies can be established by designing tourism VR programs for potential tourists to help them experience and choose appropriate destinations before actual visitation.

\section{Limitations and Future Study Directions}

Although the results of the current research provide pertinent theoretical as well as practical contributions to the field, this research has limitations that suggest future study directions. 
Because the current research model tested VR tourists in Korea, future studies may need to apply this model to other cultures or countries to make it generalizable or to determine whether any cultural difference exists. Future researchers could also examine the differences and similarities between people who visited the destination depicted in VR content and those who did not visit the destination shown in VR tourism by applying multi-group analysis to better investigate variances in behavioral gaps between the two consumer groups. In addition, future studies might examine visitors' personality (e.g., Big Five personality traits, attachment styles) as control variables. This could provide a useful extension to examine potential tourists' behaviors depending on individuals' traits. Furthermore, future studies can employ this theoretical research model to examine consumers' behaviors using augmented reality (AR) in comparison to consumers using VR so that tourism-related businesses are able to take advantage of both AR and VR technologies. The attitude-behavior relation theory has been well documented in the literature (Ajzen and Fishbein 1977; Glasman and Albarracín 2006), and future studies on VR tourism could apply attitude-behavior-context theory to better understand consumers' experiences and behavior in the VR tourism context. 


\section{References}

Ahrholdt, D. C., S. P. Gudergan, and C. M. Ringle. 2017. "Enhancing Service Loyalty: The Roles of Delight, Satisfaction, and Service Quality." Journal of Travel Research 56 (4): 436-50.

Ajzen, I., and M. Fishbein. 1977. "Attitude-Behavior Relations: A Theoretical Analysis and Review of Empirical Research.” Psychological Bulletin 84 (5): 888-918.

American Association for Public Opinion Research. 2016. "Standard Definitions: Final Dispositions of Case Codes and Outcome Rates for Surveys." Illinois: AAPOR. http://www.aapor.org/AAPOR Main/media/publications/StandardDefinitions20169theditionfinal.pdf (accessed February 03, 2018).

Arnould, E. J., and L. L. Price. 1993. "River Magic: Extraordinary Experience and the Extended Service Encounter.” Journal of consumer Research 20 (1): 24-45.

Baños, R. M., C. Botella, M. Alcañiz, V. Liaño, B. Guerrero, and B. Rey. 2004. "Immersion and Emotion: Their Impact on the Sense of Presence." CyberPsychology \& Behavior 7 (6): 734-41.

Bhattacherjee, A., and C. Sanford. 2006. "Influence Processes for Information Technology Acceptance: An Elaboration Likelihood Model.” MIS Quarterly 30 (4): 805-25.

Bitner, M. J. 1992. "Servicescapes: The Impact of Physical Surroundings on Customers and Employees.” Journal of Marketing 56 (2): 57-71.

Bowlby, J. 1951. "Maternal Care and Mental Health.” Bulletin of the World Health Organization 3 (3): 355-533.

Bowlby, J. 1977. "The Making and Breaking of Affectional Bonds. I. Aetiology and Psychopathology in the Light of Attachment Theory. An Expanded Version of the Fiftieth Maudsley Lecture, Delivered before the Royal College of Psychiatrists, 19 November 1976." British Journal of Psychiatry 130 (3): 201-10.

Brislin, R. W. 1970. "Back-Translation for Cross-Cultural Research." Journal of CrossCultural Psychology 1 (3). Sage Publications Sage CA: Thousand Oaks, CA: 185-216.

Campbell, D. T., and D. W. Fiske. 1959. "Convergent and Discriminant Validation by the Multitrait-Multimethod Matrix.” Psychological Bulletin 56 (2): 81-105.

Chang, C. H., S. Shu, and B. King. 2014. "Novelty in Theme Park Physical Surroundings: An Application of the Stimulus-Organism-Response Paradigm." Asia Pacific Journal of Tourism Research 19 (6): 680-99.

Chen, C. C., and J. Y. Yao. 2018. "What Drives Impulse Buying Behaviors in a Mobile Auction? The Perspective of the Stimulus-Organism-Response Model." Telematics and Informatics 35 (5):1249-62. 
Chen, F. F., K. H. Sousa, and S. G. West. 2009. "Testing Measurement Invariance of SecondOrder Factor Models.” Structural Equation Modeling 12 (3): 471-92.

Chin, W. W., B. L. Marcolin, and P. R. Newsted. 2003. “A Partial Least Squares Latent Variable Modeling Approach for Measuring Interaction Effects: Results from a Monte Carlo Simulation Study and Electronic-Mail Emotion/adoption Study." Information Systems Research 14 (2): 189-217.

Chin, W. W., J. B. Thatcher, and R. T. Wright. 2012. "Assessing Common Method Bias: Problems with the ULMC Technique.” MIS Quarterly (3): 1003-19.

Chin, W. W. 1998. “Overview of the PLS Method.” http://plsgraph.com/ (accessed February 2, 2018).

Chiu, C. M., Y. H. Fang, and E. T. G. Wang. 2015. "Building Community Citizenship Behaviors: The Relative Role of Attachment and Satisfaction." Journal of the Association for Information Systems 16 (11): 947-79.

Chung, J. Y., J. S. Kim, C. K. Lee, and M. J. Kim. 2018. "Slow-Food-Seeking Behaviour, Authentic Experience, and Perceived Slow Value of a Slow-Life Festival." Current Issues in Tourism 21 (2): 123-27.

Churchill Jr., G. A. 1979. “A Paradigm for Developing Better Measures of Marketing Constructs." Journal of Marketing Research 16 (1): 64-73.

Cicchetti, D. V, D. Showalter, and P. J. Tyrer. 1985. "The Effect of Number of Rating Scale Categories on Levels of Inter-Rater Reliability: A Monte-Carlo Investigation." Applied Psychological Measurement 9: 31-36.

Cohen, E. 1988. "Authenticity and Commoditization in Tourism." Annals of Tourism Research 15 (3): 371-86.

Cohen, J. 1992. “A Power Primer.” Psychological Bulletin 112 (July): 155-59.

Conway, J. M., and C. E. Lance. 2010. "What Reviewers Should Expect from Authors Regarding Common Method Bias in Organizational Research." Journal of Business and Psychology 25 (3): 325-34.

Csikszentmihalyi, M. 1975. "Beyond Boredom and Anxiety." San Francisco: Jossey-Bass.

Dewailly, J. M. 1999. "Sustainable Tourist Space: From Reality to Virtual Reality?" Tourism Geographies 1 (1): 41-55.

do Valle, P. O., and G. Assaker. 2016. "Using Partial Least Squares Structural Equation Modeling in Tourism Research: A Review of Past Research and Recommendations for Future Applications.” Journal of Travel Research 55 (6): 695-708.

Dueholm, J., and K. M. Smed. 2014. "Heritage Authenticities - A Case Study of Authenticity Perceptions at a Danish Heritage Site." Journal of Heritage Tourism 9 (4): 285-98. 
Efron, B. 1987. "Better Bootstrap Confidence Intervals." Journal of American Statistical Association 82 (397):171-85.

Embrain. 2018. "The Largest Panel in Asia: 3 Million Panelists." http://www.embrain.com/eng/ (accessed February 2, 2018).

Evans, J. R, and A. Mathur. 2005. "The Value of Online Surveys." Internet Research 15 (2): 195-219.

Fornell, C., and D. F. Larcker. 1981. "Evaluating Structural Equation Models with Unobservable Variables and Measurement Error." Journal of Marketing Research 18 (1): 39-50.

Gao, L., X. Bai, and A. Park. 2017. "Understanding Sustained Participation in Virtual Travel Communities from the Perspectives of Is Success Model and Flow Theory." Journal of Hospitality and Tourism Research 41 (4): 475-509.

Gilmore, J. H, and B. J. Pine. 2007. Authenticity: What Consumers Really Want. Boston, Massachusetts: Harvard Business Press Center.

Glasman, L. R., and D. Albarracín. 2006. "Forming Attitudes That Predict Future Behavior: A Meta-Analysis of the Attitude-Behavior Relation." Psychological Bulletin 132 (5): 778822.

Goel, L., N. A. Johnson, I. Junglas, and B. Ives. 2011. "From Space to Place: Predicting Users' Intentions to Return to Virtual Worlds.” MIS Quarterly 35 (3): 749-71.

Gross, M. J., and G. Brown. 2008. “An Empirical Structural Model of Tourists and Places: Progressing Involvement and Place Attachment into Tourism." Tourism Management 29 (6): 1141-51.

Gupta, S., and H. Kim. 2007. "Developing the Commitment to Virtual Community:" Information Resources Management Journal 20 (1): 28-45.

Guo, Y., and S. Barnes. 2011. "Purchase Behavior in Virtual Worlds: An Empirical Investigation in Second Life." Information and Management 48 (7): 303-12.

Guttentag, D. A. 2010. "Virtual Reality: Applications and Implications for Tourism." Tourism Management 31 (5): 637-51.

Hair, J. F., W. C. Black, B. J. Babin, and R. E. Anderson. 2010. Multivariate Data Analysis. $7^{\text {th }}$ ed. Upper Saddle River NJ: Prentice Hall.

Hair, J. F., M. Sarstedt, C. M. Ringle, and J. A. Mena. 2012. "An Assessment of the Use of Partial Least Squares Structural Equation Modeling in Marketing Research." Journal of the Academy of Marketing Science 40 (3): 414-33.

Harman, D. 1967. “A Single Factor Test of Common Method Variance.” Journal of Psychology 35: 359-78. 
Henseler, J., C. M. Ringle, and M. Sarstedt. 2015. "A New Criterion for Assessing Discriminant Validity in Variance-Based Structural Equation Modeling." Journal of the Academy of Marketing Science 43 (1): 115-35.

Hobson, J. S. P., and A. P. Williams. 1995. "Virtual Reality: A New Horizon for the Tourism Industry." Journal of Vacation Marketing 1 (2): 124-35.

Holbrook, M. B., and E. C. Hirschman. 1982. "The Experiential Aspects of Consumption: Consumer Fantasies, Feelings, and Fun.” Journal of Consumer Research 9 (2): 132-40.

Holsapple, C. W., and J. Wu. 2007. "User Acceptance of Virtual Worlds: The Hedonic Framework." ACM SIGMIS Database: The DATABASE for Advances in Information Systems 38 (4). ACM: 86-89.

Huang, Y. C., S. J. Backman, and K. F. Backman. 2010. "Student Attitude toward Virtual Learning in Second Life: A Flow Theory Approach." Journal of Teaching in Travel and Tourism 10 (4): 312-34.

Huang, Y. C. S. J. Backman, and K. F. Backman. 2012. "Exploring the Impacts of Involvement and Flow Experiences in Second Life on People's Travel Intentions." Journal of Hospitality and Tourism Technology 3 (1): 4-23.

Huang, Y. C., K. F. Backman, S. J. Backman, and L. L. Chang. 2016. "Exploring the Implications of Virtual Reality Technology in Tourism Marketing: An Integrated Research Framework." International Journal of Tourism Research 18 (2): 116-28.

Huang, Y. C., S. J. Backman, K. F. Backman, and D. Moore. 2013. "Exploring User Acceptance of 3D Virtual Worlds in Travel and Tourism Marketing." Tourism Management 36: 490-501.

Ilieva, J., S. Baron, and N. M. Healey. 2002. "Online Surveys in Marketing Research: Pros and Cons." International Journal of Market Research 44 (3): 376-382.

Io, M. U., and P. Y. K. Wan. 2018. "Relationships between Tourism Experiences and Place Attachment in the Context of Casino Resorts." Journal of Quality Assurance in Hospitality and Tourism 19 (1): 45-65.

Islam, J., and Z. Rahman. 2017. "The Impact of Online Brand Community Characteristics on Customer Engagement: An Application of Stimulus-Organism-Response Paradigm.” Telematics and Informatics 34 (4):96-109.

Jacoby, J. 2002. "Stimulus-Organism-Response Reconsidered: An Evolutionary Step in Modeling (Consumer) Behavior." Journal of Consumer Psychology 12 (1): 51-57.

Jang, S., and Y. Namkung. 2009. "Perceived Quality, Emotions, and Behavioral Intentions: Application of an Extended Mehrabian-Russell Model to Restaurants." Journal of Business Research 62 (4): 451-60. 
Jani, D., and H. Han. 2015. "Influence of Environmental Stimuli on Hotel Customer Emotional Loyalty Response: Testing the Moderating Effect of the Big Five Personality Factors." International Journal of Hospitality Management 44 (January): 48-57.

Jung, T. H., and M. C. tom Dieck. 2017. "Augmented Reality, Virtual Reality and 3D Printing for the Co-Creation of Value for the Visitor Experience at Cultural Heritage Places." Journal of Place Management and Development 10 (2): 140-51.

Jung, T., M. Claudia, H. Lee, and N. Chung. 2016. "Effects of Virtual Reality and Augmented Reality on Visitor Experiences in Museum." In Information and Communication Technologies in Tourism, edited by A Inversini and R. Schegg, 621-35. Wien, New York: Springer International Publishing.

Jung, T., M. C. tom Dieck, N. Moorhouse, and D. tom Dieck. 2017. "Tourists' Experience of Virtual Reality Applications.” In 2017 IEEE International Conference on Consumer Electronics, ICCE 2017, 208-10.

Kamboj, S., B. Sarmah, S. Gupta, and Y. Dwivedi. 2018. "Examining Branding Co-Creation in Brand Communities on Social Media: Applying the Paradigm of Stimulus-OrganismResponse.” International Journal of Information Management 39: 169-85.

Kim, J., and S. J. Lennon. 2013. "Effects of Reputation and Website Quality on Online Consumers' Emotion, Perceived Risk and Purchase Intention." Journal of Research in Interactive Marketing 7 (1): 33-56.

Kim, M. J., M. Bonn, and C. K. Lee. 2017. 'Seniors' Dual Route of Persuasive Communications in Mobile Social Media and the Moderating Role of Discretionary Time." Asia Pacific Journal of Tourism Research 22 (8): 799-818.

Kim, M. J., N. Chung, C. K. Lee, and M. W. Preis. 2015. "Online Group-Buying of Tourism Products: Effects of Value and Trust on Site Attachment, Altruism, and Loyalty." Journal of Travel \& Tourism Marketing 32 (8): 935-52.

Kim, M. J., N. Chung, C. K. Lee, and M. W. Preis. 2016a. "Dual-Route of Persuasive Communications in Mobile Tourism Shopping." Telematics and Informatics 33 (2): 293-308.

Kim, M. J., N. Chung, C. K. Lee, and M. W. Preis. 2016b. "Why Do Smartphone Shoppers Help Others on Websites? The Effects of Attachments on Reciprocal Altruism." Information Development 32 (4): 920-36.

Kim, M. J., W. G. Kim, J. M. Kim, and C. Kim. 2016c. "Does Knowledge Matter to Seniors' Usage of Mobile Devices? Focusing on Motivation and Attachment." International Journal of Contemporary Hospitality Management 28 (8): 1702-27.

Kim, M. J., C. K. Lee, and M. Bonn. 2016. "The Effect of Social Capital and Altruism on Seniors' Revisit Intention to Social Network Sites for Tourism-Related Purposes.” Tourism Management 53 (April): 96-107. 
Kim, M. J., C. K. Lee, and M. Bonn. 2017. "Obtaining a Better Understanding about TravelRelated Purchase Intentions among Senior Users of Mobile Social Network Sites." International Journal of Information Management 37 (5): 484-96.

Kim, M. J., C. K. Lee, and M. W. Preis. 2016. "Seniors' Loyalty to Social Network Sites: Effects of Social Capital and Attachment." International Journal of Information Management 36 (6): 1020-32.

Kim, W. G., and Y. J. Moon. 2009. 'Customers' Cognitive, Emotional, and Actionable Response to the Servicescape: A Test of the Moderating Effect of the Restaurant Type." International Journal of Hospitality Management 28 (1): 144-56.

Korea Internet Security Agency. 2017. "Survey on Internet Use.” https://isis.kisa.or.kr/ (accessed February 8, 2017).

Kronqvist, A., J. Jokinen, and R. Rousi. 2016. "Evaluating the Authenticity of Virtual Environments: Comparison of Three Devices." Advances in Human-Computer Interaction 2937632: 1-14.

Lalicic, L., and C. Weismayer. 2018. "Being Passionate about the Mobile While Travelling." Current Issues in Tourism 21 (8): 950-63.

Lazarus, R. S. 1991. Emotion and Adaptation. New York, NY: Oxford University Press.

Lan, Y. J., and C. Y. Liao. 2018. "The Effects of 3D Immersion on CSL Students' Listening Comprehension." Innovation in Language Learning and Teaching 12 (1): 35-46.

Lee, O., and J. E. Oh. 2007. "The Impact of Virtual Reality Functions of a Hotel Website on Travel Anxiety." Cyberpsychology and Behavior 10 (4): 584-86.

Lin, C. H., and W. C. Wang. 2012. "Effects of Authenticity Perception, Hedonics, and Perceived Value on Ceramic Souvenir-Repurchasing Intention." Journal of Travel and Tourism Marketing 29 (8): 779-95.

Lindell, M. K., and D. J. Whitney. 2001. "Accounting for Common Method Variance in Cross-Sectional Research Designs.” Journal of Applied Psychology 86 (1): 114-21.

Loup, G., A. Serna, S. Iksal, and S. George. 2016. Immersion and Persistence: Improving Learners' Engagement in Authentic Learning Situations. Lecture Notes in Computer Science (Including Subseries Lecture Notes in Artificial Intelligence and Lecture Notes in Bioinformatics). Vol. 9891 LNCS.

Lowry, P. B., J. E. Gaskin, N. W. Twyman, B. Hammer, and T. L. Roberts. 2013. "Taking 'Fun and Games' Seriously: Proposing the Hedonic-Motivation System Adoption Model (HMSAM)." Journal of the Association for Information Systems 14 (11): 617-71.

Maslow, A. H. 1943. “A Theory of Human Motivation.” Psychological Review 50 (4): 37096. 
Mehrabian, A., and J. A. Russell. 1974. An Approach to Environmental Psychology. Cambridge, MA: MIT Press.

Meng, B., and K. Choi. 2016a. "Extending the Theory of Planned Behaviour: Testing the Effects of Authentic Perception and Environmental Concerns on the Slow-Tourist Decision-Making Process." Current Issues in Tourism 19 (6): 528-44.

Meng, B., and K. Choi. 2016b. "The Role of Authenticity in Forming Slow Tourists' Intentions: Developing an Extended Model of Goal-Directed Behavior." Tourism Management 57: 397-410.

Mkono, M. 2013. "Using Net-Based Ethnography (Netnography) to Understand the Staging and Marketing Of 'authentic African' dining Experiences to Tourists at Victoria Falls." Journal of Hospitality and Tourism Research 37 (2): 184-98.

Muñoz Morcillo, J., F. Schaaf, R. H. Schneider, and C. Y. Robertson-von Trotha. 2017. "Authenticity through VR-Based Documentation of Cultural Heritage. A Theoretical Approach Based on Conservation and Documentation Practices." Virtual Archaeology Review 8 (16): 35-43.

Mura, P., R. Tavakoli, and S. P. Sharif. 2017. “"Authentic but Not Too Much': Exploring Perceptions of Authenticity of Virtual Tourism." Information Technology and Tourism 17 (2): 145-59.

Nah, F. F. H., B. Eschenbrenner, D. DeWester, and S. R. Park. 2010. "Impact of Flow and Brand Equity in 3d Virtual Worlds.” Journal of Database Management 21 (3): 69-89.

Narayan, B., C. Rajendran, and L. P. Sai. 2008. "Scales to Measure and Benchmark Service Quality in Tourism Industry: A Second-Order Factor Approach.” Benchmarking 15 (4): 469-93.

Nguyen, T. H. H., and C. Cheung. 2016. "Toward an Understanding of Tourists' Authentic Heritage Experiences: Evidence from Hong Kong." Journal of Travel and Tourism Marketing 33 (7): 999-1010.

Novello, S., and P. M. Fernandez. 2016. "The Influence of Event Authenticity and Quality Attributes on Behavioral Intentions." Journal of Hospitality and Tourism Research 40 (6): $685-714$.

Oleksy, T., and A. Wnuk. 2017. "Catch Them All and Increase Your Place Attachment! The Role of Location-Based Augmented Reality Games in Changing People - Place Relations." Computers in Human Behavior 76: 3-8.

Orth, U. R., Y. Limon, and G. Rose. 2010. "Store-Evoked Affect, Personalities, and Consumer Emotional Attachments to Brands." Journal of Business Research 63 (11): $1202-8$.

Peng, C., and Y. G. Kim. 2014. "Application of the Stimuli-Organism-Response (S-O-R) Framework to Online Shopping Behavior." Journal of Internet Commerce 13:159-76. 
Pine, B. J., and J. H. Gilmore. 2015. "Authenticity."

http://www.strategichorizons.com/authenticity.html (accessed February 2, 2018).

Pine, B. J., and J. H. Gilmore. 1999. The Experience Economy. Boston, MA: Harvard Business School Press.

Pietschmann, D., G. Valtin, and P. Ohler. 2012. "The Effect of Authentic Input Devices on Computer Game Immersion." In Computer Games and New Media Cultures: A Handbook of Digital Games Studies, edited by J Fromme and A Unger, 279-92.

Podsakoff, P. M., S. B. MacKenzie, J. Y. Lee, and N. P. Podsakoff. 2003. "Common Method Biases in Behavioral Research: A Critical Review of the Literature and Recommended Remedies.” Journal of Applied Psychology 88 (5): 879-903.

Poremba, S. 2017. "How Virtual Reality and AR Will Change the Way You Shop." https://www.gearbrain.com/vr-shopping-apps-2312243800.html (accessed March 3, 2018).

Prayag, G., and C. Ryan. 2012. “Antecedents of Tourists' Loyalty to Mauritius: The Role and Influence of Destination Image, Place Attachment, Personal Involvement, and Satisfaction." Journal of Travel Research 51 (3): 342-356.

Preston, C. C., and A. M. Colman. 2000. "Optimal Number of Response Categories in Rating Scales: Reliability, Validity, Discriminating Power, and Respondent Preferences." Acta Psychologica 104 (1): 1-15.

Rajaguru, R. 2014. "Motion Picture-Induced Visual, Vocal and Celebrity Effects on Tourism Motivation: Stimulus Organism Response Model." Asia Pacific Journal of Tourism Research 19 (4): 375-88.

Ramkissoon, H. 2015. “Authenticity, Satisfaction, and Place Attachment: A Conceptual Framework for Cultural Tourism in African Island Economies." Development Southern Africa 32 (3): 292-302.

Ramkissoon, H., L. D. Graham Smith, and B. Weiler. 2013. "Testing the Dimensionality of Place Attachment and Its Relationships with Place Satisfaction and pro-Environmental Behaviours: A Structural Equation Modelling Approach.” Tourism Management 36: $552-66$.

Rick, A. 2017. "The Other Side of Singles' Day: Alibaba's Virtual Reality Testing Ground." https://www.forbes.com/sites/augustrick/2017/11/12/the-other-side-of-singles-dayalibabas-virtual-reality-testing-ground/\#676de8371c81 (accessed March 4, 2018).

Ringle, C. M., S. Wende, and J. M. Becker. 2015. "SmartPLS 3.2.7." http://www.smartpls.com (accessed February 4, 2017).

Saeed, N., Y. Yang, and S. Sinnappan. 2009. "Emerging Web Technologies in Higher Education: A Case of Incorporating Blogs, Podcasts and Social Bookmarks in a Web Programming Course Based on Students' Learning Styles and Technology Preferences." Educational Technology and Society 12 (4): 98-109. 
Schaffer, V. 2017. "Enhancing Learning to Diverse Cohorts via Immersive Visualization." Journal of Hospitality, Leisure, Sport and Tourism Education 21 (July):46-54.

Stanley, A. 2017. "Virtual Reality Experiences Becoming Big Part of Tourism Campaigns." http://www.travelweek.ca/news/virtual-reality-experiences-becoming-big-part-tourismcampaigns/ (January 16, 2018).

Tussyadiah, I. P. 2016. "The Influence of Innovativeness on On-Site Smartphone Use Among American Travelers: Implications for Context-Based Push Marketing." Journal of Travel and Tourism Marketing 33 (6): 806-23.

Tussyadiah, I. P., D. Wang, T. H. Jung, and M.C. tom Dieck. 2018. "Virtual Reality, Presence, and Attitude Change: Empirical Evidence from Tourism." Tourism Management 66: $140-54$.

Veasna, S., W. Y. Wu, and C. H. Huang. 2013. "The Impact of Destination Source Credibility on Destination Satisfaction: The Mediating Effects of Destination Attachment and Destination Image.” Tourism Management 36: 511-26.

Venkatesh, V. 2000. "Determinants of Perceived Ease of Use: Integrating Control, Intrinsic Motivation, and Emotion into the Technology Acceptance Model." Information Systems Research 11 (4): 342-65.

Wang, N. 1999. "Rethinking Authenticity in Tourism Experience.” Annals of Tourism Research 26 (2): 349-70.

Wu, Y. L., and E. Y. Li. 2018. "Marketing Mix, Customer Value, and Customer Loyalty in Social Commerce.” Internet Research 28 (1):74-104.

Williams, P., and J. P. Hobson. 1995. "Virtual Reality and Tourism: Fact or Fantasy?" Tourism Management 16 (6): 423-27.

Wolfendale, J. 2007. "My Avatar, My Self: Virtual Harm and Attachment.” Ethics and Information Technology 9 (2): 111-19.

Wohlwill, J. F. 1976. "Environmental Aesthetics: The Environment as a Source of Affect." Human Behavior and Environment 1: 37-86.

Wright, K. B. 2005. "Researching Internet-Based Populations: Advantages and Disadvantages of Online Survey Research, Online Questionnaire Authoring Software Packages, and Web Survey Services." Journal of Computer-Mediated Communication 10 (3): Degital publication.

Yoo, I. Y, T. J. Lee, and C. K. Lee. 2015. "Effect of Health and Wellness Values on Festival Visit Motivation.” Asia Pacific Journal of Tourism Research 20 (2): 152-70.

Yung, R., and C. Khoo-Lattimore. 2017. "New Realities: A Systematic Literature Review on Virtual Reality and Augmented Reality in Tourism Research." Current Issues in Tourism inpress. https://doi.org/10.1080/13683500.2017.1417359. 
Table 1. Results of Confirmatory Factor Analysis.

\begin{tabular}{|c|c|c|c|c|c|c|c|}
\hline Construct & Items & $\overline{F L}$ & $\begin{array}{c}\mathrm{t}- \\
\text { value }\end{array}$ & AVE & $\mathrm{CR}$ & $\alpha$ & rho_A ${ }^{\mathrm{a}}$ \\
\hline \multirow[t]{4}{*}{$\begin{array}{l}\text { Authentic } \\
\text { experience }\end{array}$} & $\begin{array}{l}\text { 1. Using the tourism-related VR activity } \\
\text { provided me with authentic experiences. }\end{array}$ & 0.824 & 41.342 & 0.737 & 0.918 & 0.881 & 0.881 \\
\hline & $\begin{array}{l}\text { 2. Using the tourism-related VR activity } \\
\text { provided me with genuine experiences. }\end{array}$ & 0.868 & 52.758 & & & & \\
\hline & $\begin{array}{l}\text { 3. Using the tourism-related VR activity } \\
\text { provided me with exceptional } \\
\text { experiences. }\end{array}$ & 0.882 & 61.846 & & & & \\
\hline & $\begin{array}{l}\text { 4. Using the tourism-related VR activity } \\
\text { provided me with unique experiences. }\end{array}$ & 0.859 & 48.231 & & & & \\
\hline \multirow[t]{4}{*}{$\begin{array}{l}\text { Cognitive } \\
\text { response }\end{array}$} & $\begin{array}{l}\text { 1. I gain knowledge from using the } \\
\text { tourism-related VR activity. }\end{array}$ & 0.897 & 66.076 & 0.738 & 0.918 & 0.880 & 0.883 \\
\hline & $\begin{array}{l}\text { 2. Using the tourism-related VR activity is } \\
\text { useful to collect information. }\end{array}$ & 0.896 & 64.019 & & & & \\
\hline & $\begin{array}{l}\text { 3. Using the tourism-related VR activity is } \\
\text { beneficial. }\end{array}$ & 0.872 & 42.146 & & & & \\
\hline & $\begin{array}{l}\text { 4. Using the tourism-related VR activity } \\
\text { allows me to form friendships with other } \\
\text { users. }\end{array}$ & 0.766 & 23.358 & & & & \\
\hline \multirow[t]{4}{*}{ Enjoyment } & $\begin{array}{l}\text { 1. Using the tourism-related VR activity is } \\
\text { enjoyable for me. }\end{array}$ & 0.918 & 80.755 & 0.829 & 0.951 & 0.931 & 0.932 \\
\hline & $\begin{array}{l}\text { 2. Using the tourism-related VR activity is } \\
\text { pleasurable for me. }\end{array}$ & 0.943 & 136.466 & & & & \\
\hline & $\begin{array}{l}\text { 3. Using the tourism-related VR activity is } \\
\text { fun for me. }\end{array}$ & 0.904 & 69.773 & & & & \\
\hline & $\begin{array}{l}\text { 4. Using the tourism-related VR activity } \\
\text { keeps me happy. }\end{array}$ & 0.876 & 59.160 & & & & \\
\hline \multirow[t]{3}{*}{$\begin{array}{l}\text { Emotional } \\
\text { involvement }\end{array}$} & $\begin{array}{l}\text { 1. I am completely involved in the tourism- } \\
\text { related VR activity. }\end{array}$ & 0.863 & 55.712 & 0.806 & 0.926 & 0.879 & 0.881 \\
\hline & $\begin{array}{l}\text { 2. I am deeply impressed by the tourism- } \\
\text { related VR activity. }\end{array}$ & 0.912 & 95.851 & & & & \\
\hline & $\begin{array}{l}\text { 3. I feel total empathy with the tourism- } \\
\text { related VR activity. }\end{array}$ & 0.918 & 94.787 & & & & \\
\hline \multirow[t]{4}{*}{ Flow state } & $\begin{array}{l}\text { 1. When I am using the tourism-related VR } \\
\text { activity, I feel totally captivated. }\end{array}$ & 0.863 & 55.001 & 0.767 & 0.908 & 0.848 & 0.848 \\
\hline & $\begin{array}{l}\text { 2. When I am using the tourism-related VR } \\
\text { activity, time seems to pass very quickly. }\end{array}$ & 0.897 & 65.780 & & & & \\
\hline & $\begin{array}{l}\text { 3. When I am using the tourism-related VR } \\
\text { activity, I forget all concerns. }\end{array}$ & 0.868 & 54.257 & & & & \\
\hline & $\begin{array}{l}\text { 4. Using the tourism-related VR activity } \\
\text { often makes me forget where I am.* }\end{array}$ & - & - & & & & \\
\hline \multirow[t]{4}{*}{ Attachment } & $\begin{array}{l}\text { 1. I am closely related to the content when } \\
\text { using the tourism-related VR activity. }\end{array}$ & 0.878 & 62.712 & 0.829 & 0.951 & 0.931 & 0.934 \\
\hline & $\begin{array}{l}\text { 2. Using the tourism-related VR activity is } \\
\text { part of my life. }\end{array}$ & 0.909 & 82.903 & & & & \\
\hline & $\begin{array}{l}\text { 3. I am attached to using the tourism- } \\
\text { related VR activity. }\end{array}$ & 0.930 & 118.795 & & & & \\
\hline & $\begin{array}{l}\text { 4. Using the tourism-related VR activity is } \\
\text { important to me. }\end{array}$ & 0.925 & 105.897 & & & & \\
\hline \multirow[t]{4}{*}{$\begin{array}{l}\text { Visit } \\
\text { intention }\end{array}$} & $\begin{array}{l}\text { 1. I am planning to visit the place that I } \\
\text { observed in the tourism-related VR } \\
\text { activity. }\end{array}$ & 0.913 & 80.436 & 0.858 & 0.960 & 0.945 & 0.945 \\
\hline & $\begin{array}{l}\text { 2. I intend to visit the place that I saw in } \\
\text { the tourism-related VR activity in near } \\
\text { future. }\end{array}$ & 0.930 & 103.127 & & & & \\
\hline & $\begin{array}{l}\text { 3. I am willing to visit the place that I saw } \\
\text { in the tourism-related VR activity soon. }\end{array}$ & 0.930 & 99.025 & & & & \\
\hline & $\begin{array}{l}\text { 4. I intend to invest money and time to visit } \\
\text { the place that I observed in the VR } \\
\text { tourism. }\end{array}$ & 0.931 & 122.553 & & & & \\
\hline
\end{tabular}

Note: $*$ items were deleted according to confirmatory factor analysis; FL = factor loadings; AVE = average variance extracted; $\mathrm{CR}=$ composite reliability; $\alpha=$ Cronbach's alpha. ${ }^{a}$ reliability coefficient (cutoff $>0.7$ ). 
Table 2. Heterotrait-Monotrait Ratio of Correlations (HTMT).

\begin{tabular}{lccccccc}
\hline Construct & \multicolumn{7}{c}{ Correlation of the Constructs } \\
& $(1)$ & $(2)$ & $(3)$ & $(4)$ & $(5)$ & $(6)$ & $(7)$ \\
\hline (1) Authentic experience & & & & & & & \\
(2) Cognitive response & 0.591 & & & & & & \\
(3) Enjoyment & 0.656 & 0.594 & & & & & \\
(4) Emotional involvement & 0.721 & 0.644 & 0.722 & & & & \\
(5) Flow state & 0.623 & 0.451 & 0.663 & 0.683 & & & \\
(6) Attachment & 0.598 & 0.681 & 0.558 & 0.676 & 0.515 & & \\
(7) Visit intention & 0.475 & 0.639 & 0.507 & 0.549 & 0.397 & 0.620 & \\
Effect size (f) & & 0.378 & 4.431 & 2.891 & 1.884 & 0.378 & 0.198 \\
Effect size (q $\left.q^{2}\right)$ & & 0.189 & 0.645 & 0.567 & 0.473 & 0.371 & 0.348 \\
Mean* & 4.536 & 4.586 & 4.991 & 4.387 & 4.591 & 3.835 & 4.262 \\
Standard deviation & 1.002 & 1.028 & 1.006 & 1.122 & 1.098 & 1.255 & 1.291 \\
\hline
\end{tabular}

Note: *7-point Likert scale. 
Table 3. Mediating Effects.

\begin{tabular}{llll}
\hline Path & Direct Effect & $\begin{array}{l}\text { Indirect Effect } \\
\text { (Mediation) }\end{array}$ & Total Effect \\
\hline Authentic experience $\rightarrow$ Cognitive response & $0.524^{* * *}$ & & $0.524 * * *$ \\
Authentic experience $\rightarrow$ Affective response & $0.521^{* * *}$ & $0.166^{* * *}$ & $0.687 * * *$ \\
Authentic experience $\rightarrow$ Attachment to VR & & $0.470^{* * *}$ & $0.470^{* * *}$ \\
Authentic experience $\rightarrow$ Visit intention & & $0.409 * * *$ & $0.409 * * *$ \\
Cognitive response $\rightarrow$ Affective response & $0.316^{* * *}$ & & $0.316^{* * *}$ \\
Cognitive response $\rightarrow$ Attachment to VR & $0.387^{* * *}$ & $0.123^{* * *}$ & $0.510^{* * *}$ \\
Cognitive response $\rightarrow$ Visit intention & $0.308^{* * *}$ & $0.201 * * *$ & $0.509 * * *$ \\
Affective response $\rightarrow$ Attachment to VR & $0.389 * * *$ & & $0.389 * * *$ \\
Affective response $\rightarrow$ Visit intention & $0.159 *$ & $0.115^{* * *}$ & $0.274 * * *$ \\
Attachment to VR $\rightarrow$ Visit intention & $0.295^{* * *}$ & & $0.295^{* * *}$ \\
\hline
\end{tabular}

Note: $* * * \mathrm{p}<0.001 ; * \mathrm{p}<0.05$. 


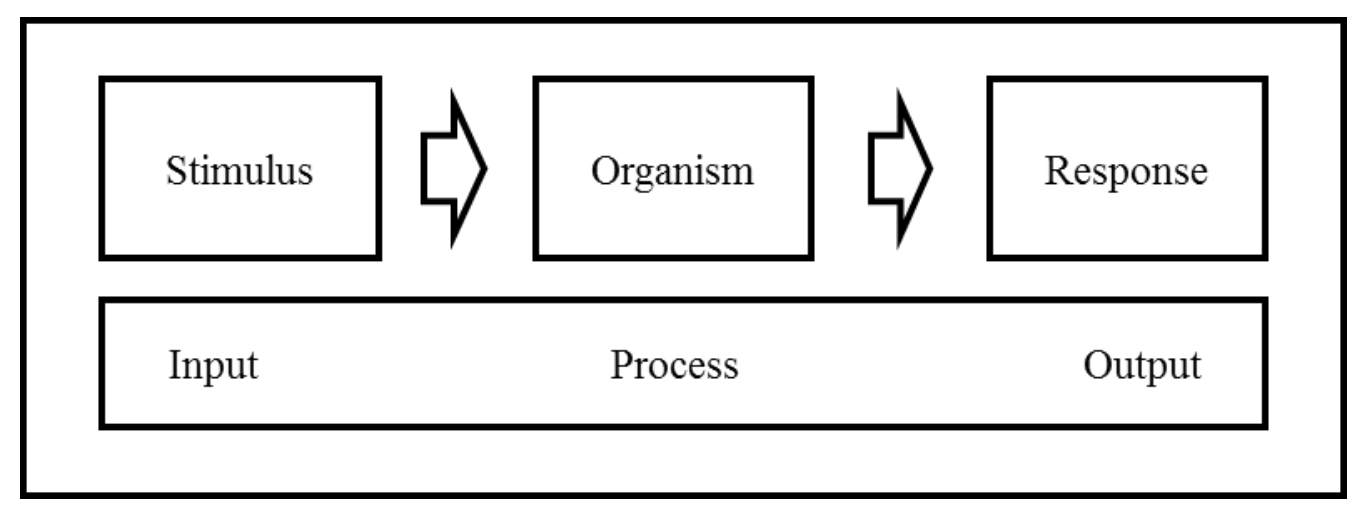

Figure 1. Conceptual framework of S-O-R theory. 


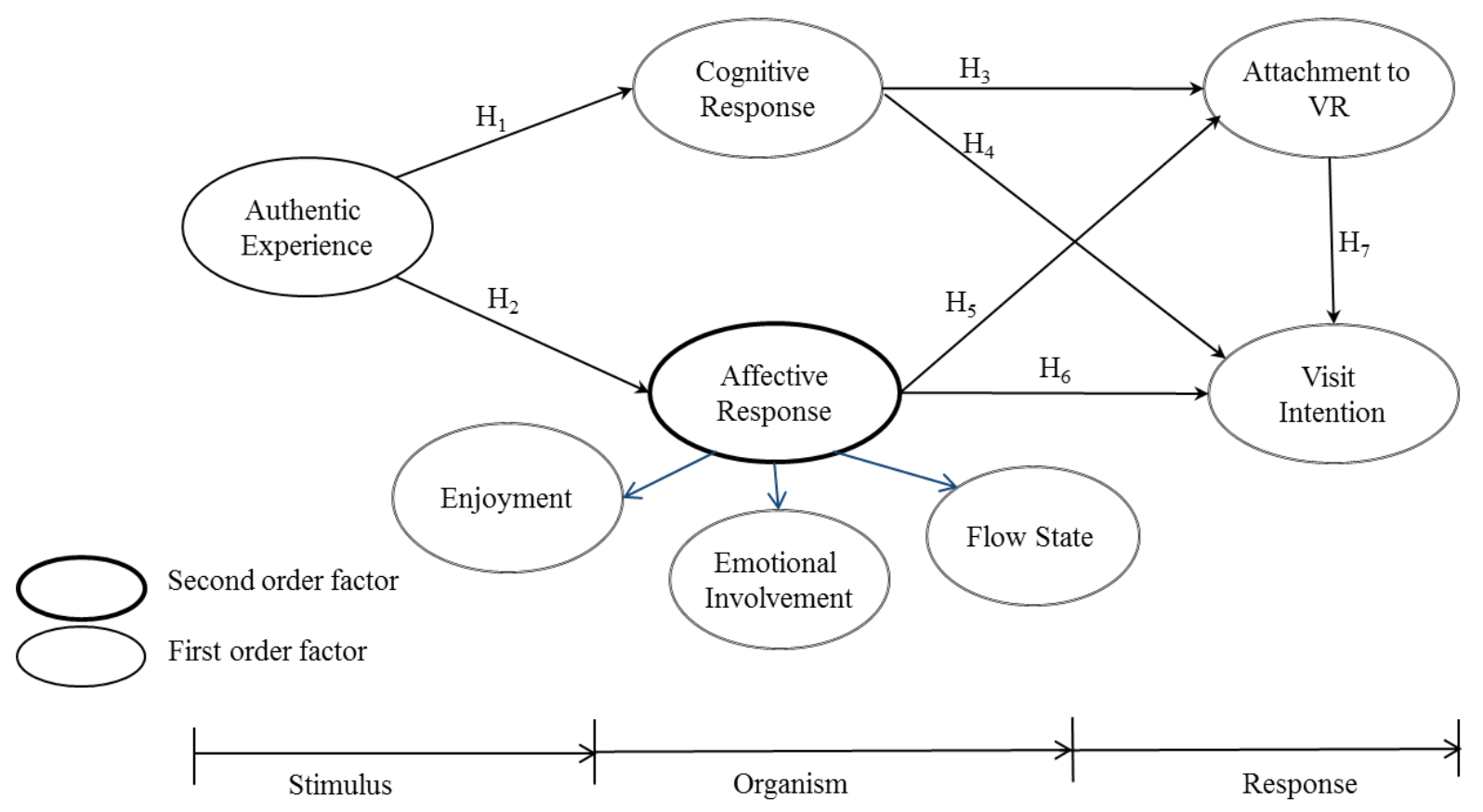

Figure 2. Proposed research model. 


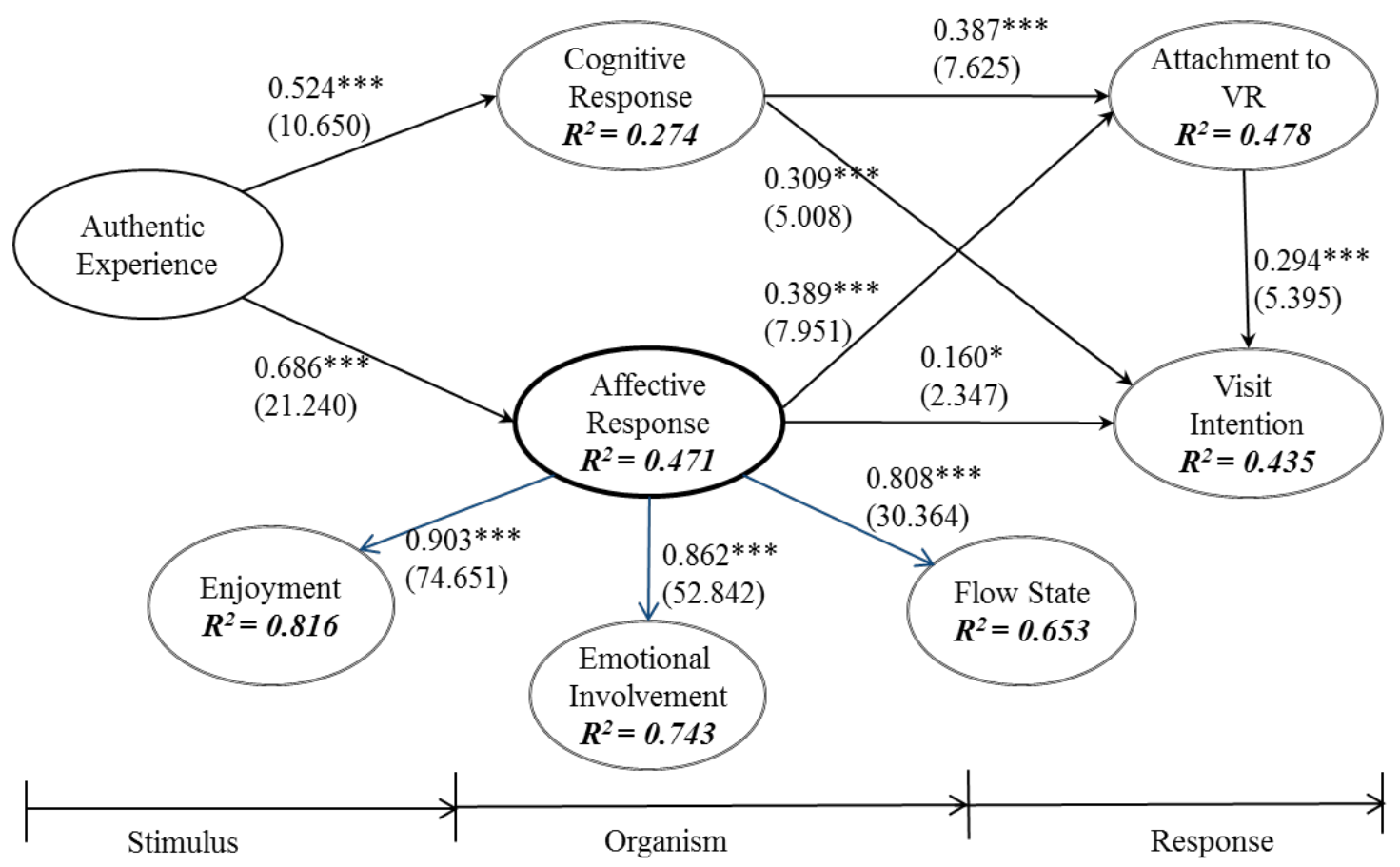

Note: ${ }^{* * *} \mathrm{p}<0.001 ;{ }^{*} \mathrm{p}<0.05$. The figures in parentheses are $\mathrm{t}$-value.

Figure 3. Results of path analysis. 


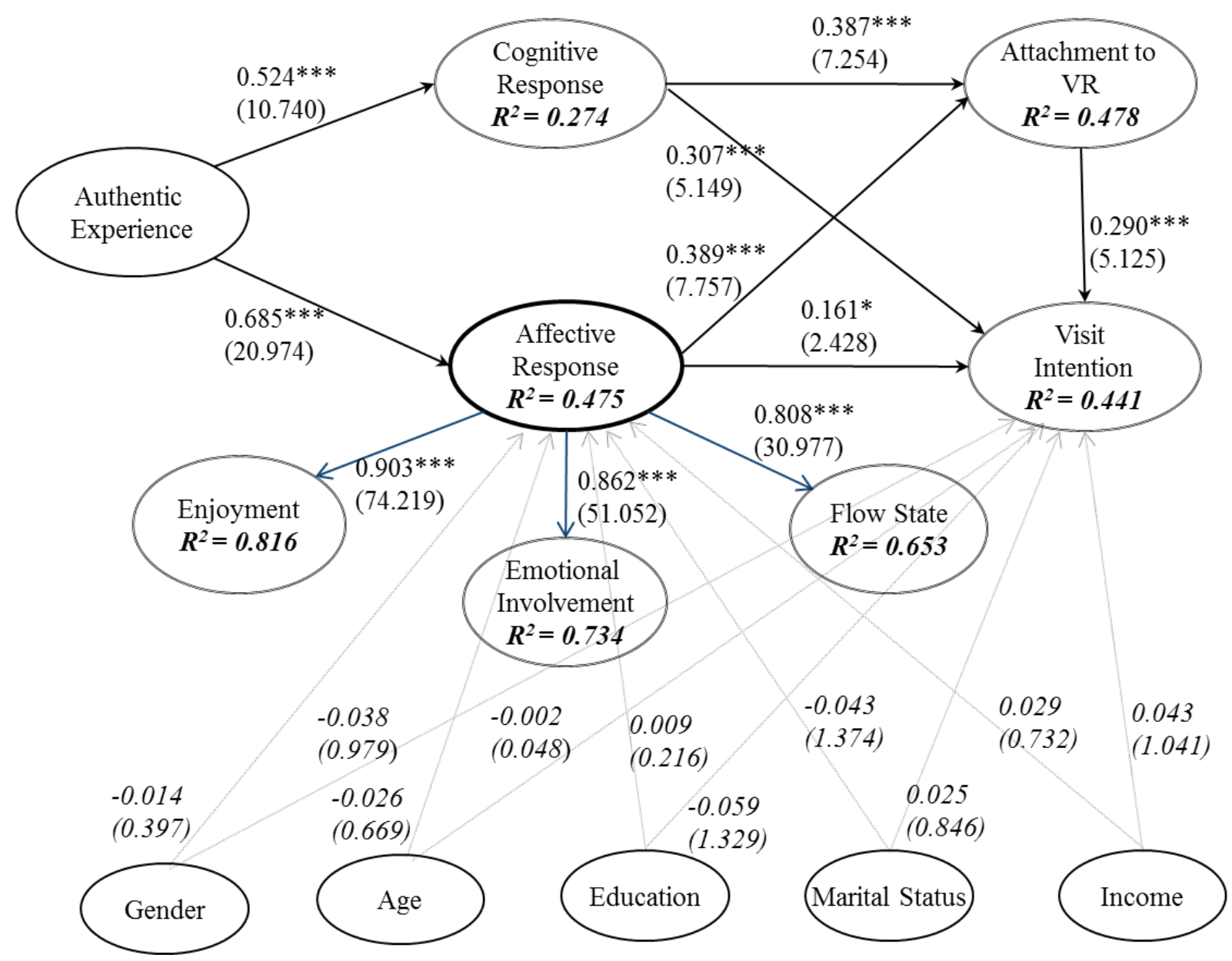

Note: $* * * \mathrm{p}<0.001 ;{ }^{*} \mathrm{p}<0.05$. The figures in parentheses are $\mathrm{t}$-values. Italic figures are insignificant.

Figure 4. Estimation of the research model considering control variables. 